\title{
LAS DIMENSIONES VISIBLES E INVISIBLES DE LA VIDA SOCIAL. NARRATIVAS DEL PADECIMIENTO ENTRE LOS CHAMULAS
}

\author{
Enrique Eroza Solana \\ enriquesol@yahoo.com \\ CIESAS Sureste \\ México
}

\section{RESUMEN}

A través del análisis de constructos narrativos en torno a experiencias del padecimiento entre los chamulas, se exploran los significados de los elementos constitutivos del marco interpretativo de las comentadas. Destaca en primer término lo que llamo «el diálogo con el cuerpo», que da cuenta de la combinación de diversas opciones de atención a la salud basadas en el tratamiento de síntomas y de reacciones derivadas del mismo, a menudo vinculadas con la dualidad frío/calor, pero sobre todo a la capacidad corporal para mantenerse activo. Destaca, asimismo, el impacto que las emociones tienen, ya sea como detonantes de padecimientos o como obstáculos para recuperar la salud; se describe al respecto la relevancia de los procesos sociales vigentes. Por último, se analiza la articulación de ideas relativas al castigo divino, la brujería y las concepciones espirituales, que en su conjunto da cuenta de una visión incierta y a la vez conflictiva e inconsistente de la vida social, que modula las visiones locales en torno a la enfermedad y el infortunio.

Palabras clave: chamulas, padecimiento, emociones. 


\section{ABSTRACT}

Through an analysis of the narrative constructs around the experiences of suffering among Chamula indigenous people, the author explores the meanings of the constitutive elements of the corresponding interpretive framework. What is outstanding, first of all, is what the author refers to as dialogue with the body, describing a combination of diverse options for health care, based on the treatment of symptoms and reactions to treatment, frequently linked to the cold-warm duality, but especially to the body's capacity for maintaining itself active. Also worth noting are the impacts from emotions, whether as triggers for one's suffering, or as obstacles to recuperating one's health. And in this regard, the relevance of current social processes is also described. Lastly, the author describes and analyzes the articulation of ideas related to divine punishment, witchcraft and spiritual conceptions - which together describe a vision that is uncertain as well as conflictive and inconsistent with social life, and that shapes the local visions related to sickness and misfortune.

Key words: chamulas, suffering, emotions. 
El presente trabajo se basa en el análisis de constructos narrativos en torno a las experiencias del padecimiento entre los tsotsiles de San Juan Chamula. Aunque involucró mayormente a personas con enfermedades crónico-degenerativas, se privilegió un enfoque independiente del de la biomedicina, con el fin de incluir experiencias del padecer construidas desde la perspectiva de los enfermos, sin que en ello necesariamente mediase un diagnóstico de carácter biomédico.

Este enfoque tiene que ver con experiencias previas de investigación en la región de Los Altos de Chiapas, a través de las cuales he observado que los padecimientos y demás infortunios se inscriben dentro de un marco interpretativo más amplio, por regla general, sólo parcialmente alterado por la influencia de la medicina académica.

El estudio tampoco estableció de antemano un perfil particular de informantes, como lo podrían ser, por ejemplo, criterios de edad, sexo, escolaridad, etc., lo que resulta de interés para la epidemiología. Los hallazgos aquí expuestos se basan en 33 casos; algunos documentados mediante entrevistas con las personas enfermas, otros con sus familiares, y en varios más con ambos. En su mayoría se refieren a hombres y mujeres de 40 años y más. Los relativos a infantes, dos casos, fueron referidos por sus madres.

El objetivo consistió en establecer la lógica que los individuos y su círculo social articulaban en torno a sus padecimientos y a las elecciones entre las diversas opciones de atención a la salud. Con ello, se buscó también identificar y analizar procesos más amplios que en el ámbito de la familia y de la comunidad intervienen, para con ello develar el lenguaje sociocultural expresado en las narrativas del padecimiento,

Desde esta perspectiva, la propuesta metodológica buscó identificar, por un lado, las situaciones de drama social, definidas por Turner (1968), quien ha mostrado que los padecimientos resultan tierra fértil para revelar tensiones y poner a prueba los valores en los que se sustentan las alianzas presupuestas por las estructuras sociales. Se exploran, por tanto, a través de la subjetividad de los narradores, las relaciones sociales y los valores atribuidos a las mismas, al verse confrontadas con las situaciones de drama. Con 
base en ello se observa también la forma en que los propios narradores confieren sentido a sus experiencias; cómo se posicionan en contextos específicos de interacción, de historia y de valores compartidos (Skultans 1998), y cómo, en consecuencia, sitúan los eventos en un orden significativo de tiempo (Good 1990).

Como he anticipado, en algunos casos, los testimonios no fueron proporcionados por la persona enferma, sino por alguno de sus familiares, aun cuando ésta se mantuvo presente. En parte, ello se debió al hecho de que se declarase, dada su condición, imposibilitada para hacerlo, pero también a arreglos tácitos establecidos dentro del grupo familiar, acerca de quién debía asumir el rol de interlocutor con el investigador. En ciertas ocasiones lo hacía, por ejemplo, quien tenía mayor dominio del castellano, o bien quien mayor acompañamiento había mantenido con la persona enferma. En otros casos, dado que varios miembros de la familia estuvieron presentes, la entrevista fue realizada con la participación de varios de ellos.

Aunque esto tendió a inhibir la opción de documentar el sentir personal del enfermo, permitió identificar los dramas familiares y comunitarios en torno a la experiencia, así como otras situaciones vinculadas por los informantes a la misma. Así, las narrativas dieron cuenta de un marco interpretativo que articula las experiencias del padecimiento con otros infortunios que alternativa o indistintamente afectaban al individuo enfermo y a los miembros de su círculo social más cercano.

Ello denotó ansiedades en torno al carácter conflictivo e inequitativo de la vida social de los informantes, así como de sus posturas y sentires personales en interpelación con los valores colectivos. Por lo mismo, también dio cuenta del papel de las emociones dentro de estas experiencias y de las situaciones que las originan, tanto en calidad de detonantes de padecimientos, como de factores que impiden recuperar la salud.

De tal suerte, el tema de las emociones constituye también un referente analítico de primera importancia, y por lo mismo vale la pena exponer algunas de sus posibilidades en el análisis antropológico. 
Uno de los temas centrales en torno al estudio de las emociones es el de su naturaleza; es decir, si están fundamentadas en el sustrato biológico del cuerpo humano, o si por el contrario son esencialmente un producto de la cultura. En términos generales, ello ha dado pie a una miríada de concepciones duales, que reflejan por un lado sesgos epistémicos, y por otro sesgos relacionados con valoraciones culturales y sociales.

Lutz (1986: 290) presenta un listado de estas dualidades y de sus implicaciones, para ello parte de la dicotomía entre emoción y pensamiento. Señala que emoción es a pensamiento como energía es a información, como corazón es a cabeza, irracional es a racional, preferencia es a inferencia, impulso es a intención, vulnerabilidad es a control, caos es a orden, valor es a hecho o conocimiento, lo relativamente inconciente es a lo relativamente conciente, subjetivo es a objetivo, físico es a mental, natural es a cultural, expresivo es a instrumental o práctico, moralmente sospechoso es a éticamente maduro, clases bajas son a las altas, niño es a adulto y lo que femenino es a masculino.

La autora sostiene que si bien el nivel de extrapolación entre estos pares puede variar dentro de las sociedades occidentales, los sesgos evaluativos en cada uno de ellos evidencia el sesgo en la distinción misma entre emoción y pensamiento, es decir, como lo inferior es a lo superior, lo relativamente malo a lo relativamente bueno.

De frente a estas oposiciones, pese al reconocimiento de la dificultad de establecer demarcaciones entre los dominios de la naturaleza y de la cultura, las ciencias sociales de corte construccionista, en especial la Antropología, tienden a privilegiar los determinantes culturales a la hora de discernir acerca de las emociones, especialmente en contextos no occidentales. Destaca en estas visiones la idea de que las emociones se expresan a través de una lógica articulada por la totalidad del sistema cultural.

Para Dewight (1989), por ejemplo, el término de estilo emocional busca facilitar la discusión y la comprensión del rol de la cultura en el ordenamiento de nuestras vidas emocionales. Busca subrayar las formas vitales en las que el dominio de las emociones 
es vinculado a otros en el sistema cultural. También pretende profundizar nuestra atención de la dialéctica cotidiana entre pensamiento, sentimiento, acto y moralidad.

Similarmente, Wikan (1989) refiere que entre los balineses la expresión emocional participa tanto de pensamiento como de sentimiento, por lo que el cometido de hacerse aparecer alegre o feliz, sentimientos que conducen a la salud, son alentados desde la tristeza. Que se trata por tanto de una preocupación colectiva, concebida como algo que fácilmente se trasmite de una persona a otra; con lo que los balineses están a través de ella bajo una obligación moral/social para manejar sus corazones, para presentar al mundo un rostro brillante y, claro, a favor de la salud del prójimo y de la propia.

Sin duda, el análisis de la dialéctica de las emociones ha hecho grandes avances en el esfuerzo de superar dicotomías, como mente/cuerpo y racionalidad/irracionalidad, así como en el estudio situado de las mismas, y de las áreas de la vida social con las que se interpelan, tanto en sus dimensiones cotidianas como extraordinarias. En dicha dialéctica, un eje de gran centralidad se refiere a todo cuanto media entre el individuo y su entorno social, por ejemplo, todo cuanto las emociones reflejan respecto a la tensión entre valores que entran en juego entre ambos, lo cual, por el peso que se le otorga a los determinantes socioculturales, no resulta del todo observable en trabajos como los anteriores.

Roseman (1990) sostiene que si bien es fácil tipificar al yo sociocéntrico como un estado estático, una escena idílica de entidades interconectadas en el que la separación y alienación no son problema, en realidad las sociedades que posicionan al yo sociocéntrico están exhibiendo sus mayores preocupaciones en torno a la relación entre el yo y el otro, cuando elaboran los conceptos y acciones que formulan y continuamente reivindican al yo sociocéntrico. Para éstas, la belleza de la interconectividad con la comunidad y la naturaleza es plasmada por la preocupación en torno a la integridad del yo. Los conceptos Temiar: permeable, múltiple, y egos desvinculables, posibilitan un sentido especial de camaradería con los humanos y no humanos con su universo social, pero esta red de apoyo es también matizada con peligro, espíritus guía benevolentes 
están allí para ser encontrados en sueños y en trance, no obstante estos contextos son temporal y espacialmente controlados para evitar contacto excesivo que pudiese ser socialmente disruptivo, la pérdida de la sombra es considerada consecuencia de ello, por lo que constituye un mecanismo para establecer o restablecer balance.

En referencia a esta tensión, también es posible una abierta discrepancia entre las emociones normadas y las que la gente expresa a partir de sus experiencias, dentro de un mismo sistema de valores. De acuerdo con Reddy (1999) ello supone la dificultad de improvisar una variación personal ad hoc respecto a las normas prevalecientes, lo que también supone un conflicto y una necesidad de navegación entre las emociones para hacer uso asertivo de las mismas. El autor sostiene que enfocar este conflicto posibilitaría escribir una historia de las emociones basada en el rango de prácticas verdaderas, en el estilo emocional normativo, y en la navegación e improvisación de los individuos, es decir, en el descubrimiento y manejo de sus emociones.

Resulta también pertinente situar este enfoque en contextos más específicos, lo que no significa pretender caer en los excesos del relativismo cultural. Rosenwein (2002) introduce el término de comunidades emocionales implicando contextos tales como familias, vecindarios, parlamentos, gremios, monasterios, parroquianos de la iglesia, etc., en los que ella propone develar sistemas de sentimiento, que estas comunidades y sus miembros definen y establecen como valioso o nocivo; las evaluaciones que hacen acerca de las emociones de los otros; la naturaleza de los lazos afectivos entre la gente que ellos reconocen y los modos de expresión emocional que ellos esperan, motivan, loan y deploran. Agrega que la gente se mueve con autonomía de una comunidad a otra, ajustando sus despliegues emocionales y sus juicios de condena o de pesar — con mayores o menores grados de éxito- hacia estos diferentes ambientes. Asume además que culturas en competencia tienen cabida en la misma persona, que no solo cada sociedad forma, constriñe y expresa emociones diferentemente, aun dentro de la misma, valores y modelos contradictorios, así como individuos, encuentran su lugar. 
Sin embargo, esta dialéctica supone una mucha mayor agencia y por ende un mucho mayor campo de acción dentro de dichas comunidades, por parte de los individuos al situar en el escenario social sus emociones y ponerlas en juego.

Rebhun (1993) identifica el aspecto interpretativo e interpersonal de las emociones; refiere que si bien los patrones de los sentimientos varían entre culturas y entre roles dentro de una misma cultura, las emociones son también caprichosas y teatrales, por tanto esenciales para las micropolíticas del poder. Mediante el análisis del concepto de nervios, como experiencia de padecimiento entre los habitantes del noreste de Brasil, argumenta que la definición de las emociones como pasiones irracionales puede participar de estrategias calculadas de manipulación interpersonal dentro de un dado espacio colectivo de valores y expectativas compartidas.

Destaca al respecto que si bien la autora identifica el rol performativo de los nervios, también da cuenta de un verdadero proceso somático que plantea la necesidad de reflexionar acerca de los constreñimientos de la Biología por un lado y de las ciencias sociales por otro, en torno a las emociones y por extensión al cuerpo humano.

Al analizar las implicaciones epistémicas de la distinción entre significado y sentimiento, Leavitt (1996) menciona que si bien individuos posicionados en ambos lados han buscado atravesarla, la vinculación de significado a lo particularmente cultural y sentimiento con lo universalmente biológico suele aún forjar explicaciones biológicas de lo familiar e interpretaciones culturales de lo extraño. Al respecto sostiene que una base biológica no es solo responsable de las semejanzas, también aporta el material de la variación. Es la específica naturaleza compartida de la biología humana que posibilita la variedad de lenguajes humanos, culturas, y patrones sociales, aun así, la variación no es infinita, y un construccionismo social liberado de presupuestos cognitivos puede conducir hacia el reconocimiento de que las sociedades también comparten muchas características y que estas similitudes, como las diferencias, pueden estar en el cuerpo. 
En concordancia con ello, Lyon (1995) se pronuncia por un entendimiento expandido de la emoción y de su ontología social y biológica para superar las limitaciones del constructivismo social. Por tomar en cuenta las relaciones sociales formales, como el poder y el estatus que operan estructural e independientemente del contexto cultural; y también por superar, desde las ciencias sociales, el miedo a la Biología para así recorporizar la Antropología y situar su mirada en sujetos corporizados a la hora de buscar entender la experiencia y el comportamiento humano.

Dentro del campo de la salud y la enfermedad, en las experiencias del padecimiento las emociones encuentran un espacio privilegiado para dar cuenta de todas estas dimensiones.

Sheper-Huges y Lock (1987), por ejemplo, distinguen en el ámbito conceptual tres cuerpos. El primero se refiere al cuerpo fenomenológicamente vívido -el cuerpo individual del yo-; el segundo al cuerpo social, entendido como un símbolo natural que permite pensar acerca de la relaciones entre naturaleza, sociedad y cultura», haciendo eco de la aserción de Douglas M. (1973) en el sentido de que todo puede simbolizar al cuerpo y el cuerpo puede simbolizarlo todo. En estrecha relación con el segundo, el tercero es el cuerpo político como medio de control social. Dada la virtud de simbolizarse mutuamente, en particular fren00te a situaciones de crisis, los tres cuerpos confluyen para resaltar las fronteras culturales que buscan pautar el comportamiento.

La demarcación de estos tres ámbitos conceptuales constituye un intento por establecer un puente decisivo entre conceptos duales e identificar su mediación, que para estas autoras se basa en las emociones, que desde su perspectiva, afectan la manera en la que el cuerpo, la enfermedad y el dolor son vivenciados y proyectados en imágenes reveladoras del buen o el pobre funcionamiento del cuerpo social y político.

Entre los chamulas, el rol de las emociones en las experiencias del padecimiento también ha sido documentado. Groark (2005) da cuenta de la influencia de las emociones negativas, que él denomina patogénicas, y que median entre la mente y el 
cuerpo, el individuo y la sociedad, y entre el pensamiento y la emoción. Se trata, por un lado, de emociones hostiles de otros, que son capaces de penetrar las fronteras corporales propias, pero también de un rango de emociones que son capaces de matar a quien las experimenta.

Como se verá, la presencia de las emociones negativas, y en cierto modo el imaginario en torno a ellas, fue un tema recurrente y de muchas formas presente en las narrativas. En primera instancia, como ya he referido, como un factor detonante de los padecimientos, y un obstáculo para recuperar la salud, pero como se verá también dieron cuenta de muchas otras posibilidades. Es importante sin embargo tener presente, al menos parcialmente, el contexto sociocultural en el que las emociones de los chamulas están teniendo lugar.

\section{EL CONTEXTO DE LOS CHAMULAS CONTEMPORÁNEOS}

Sin asumir que las tendencias de cambio, llegadas desde el exterior a San Juan Chamula, tengan una presencia reciente, se puede decir al menos que en lo que va del siglo en curso existen algunas que parecen estar impactando de muchas formas la vida de sus habitantes. En su mayoría, se trata de tendencias dinamizadas por trasformaciones económicas que en gran medida se fundamentan en un gradual colapso de la agricultura de subsistencia.

Esta situación ha impelido a los chamulas a insertarse en actividades económicas diversas, dentro y fuera de su territorio municipal. Se puede hablar, por un lado, de una creciente dependencia del trabajo asalariado e informal, de igual manera a partir de ésta es también posible observar una cada vez más amplia participación en actividades comerciales. Sin embargo, ello ha tenido lugar de manera paralela a un proceso de estratificación social iniciado varias décadas atrás, en que tanto los chamulas como los demás grupos tsotsiles y tseltales de Los Altos de Chiapas se han visto inmersos (Rus 1995). 
La participación de los chamulas en otros campos económicos se ha caracterizado por ser desigual y genera, por lo mismo, acentuadas inequidades cuyo impacto se ve reflejado en diversos aspectos de la vida social, que a su vez repercuten de manera diferencial en las condiciones de vida y por ende en los niveles de bienestar. Es de obviar también que todo ello tiene lugar en plena interdependencia con procesos económicos más amplios en los ámbitos regional, nacional e internacional, que pueden ser pensados como un contínuum respecto a procesos históricos de largo plazo.

Angulo (2008) refiere que la migración que los indígenas de Los Altos de Chiapas emprendían desde finales del siglo XIX hacia las fincas cafetaleras del Soconusco, constituye un proceso que habiendo iniciado como un mecanismo de explotación de mano de obra indígena por parte de finqueros alemanes, desde la perspectiva de los propios indígenas se trasformaría en una estrategia tendiente a complementar algunas necesidades relacionadas con el ciclo agrícola en el cual basaban su subsistencia. En relación con ello, las prácticas migratorias se hicieron extensivas hacia los valles centrales del estado (ibíd.). No obstante, dado el paulatino colapso de la agricultura, el carácter y el sentido de las prácticas migratorias se fue reorientando.

Poco a poco centros urbanos como la ciudad de México, Villahermosa y Cancún, se convirtieron en polos de atracción para los chamulas. Sin embargo, no se puede dejar del lado el fenómeno migratorio hacia San Cristóbal, que si bien en el caso de los chamulas comenzó en mayor escala a partir de conflictos político/religiosos, hoy la presencia de ellos en esta ciudad, tal y como ocurre con otros indígenas de la región y del estado, responde a múltiples causas, aunque un gran detonador fue el movimiento zapatista, que en primera instancia propició la llegada de muchos desplazados. Con el tiempo, sin embargo, la migración indígena en general y chamula en particular hacia San Cristóbal también comenzó a responder a propósitos relacionados con el estudio y el trabajo; por lo mismo, da también cuenta de un componente significativo de población juvenil, cuyas expectativas para un futuro no se encuentran en sus comunidades de origen. No obstante, a partir de hace alrededor de diez años, la migración indígena desde Los Altos de Chiapas, incluyendo a los chamulas, ha adoptado un carácter internacional, dado el creciente flujo hacia Estados Unidos. 
En esta tendencia han operado políticas económicas que paulatinamente abrieron los horizontes a los chamulas para emprender la migración hacia zonas más distantes. Por ejemplo, algunos jóvenes han dado cuenta de sus experiencias de trabajo en Tijuana, desde donde existe toda una estrategia de reclutamiento laboral de parte de industrias tales como la electrónica y de ensamblaje, que han establecido mecanismos de contratación en Tuxtla Gutiérrez en los que suelen participar empleados de origen chiapaneco que han alcanzado cierto estatus laboral que les confiere el rol de contratistas de mano de obra.

De igual modo es posible observar una vez por semana, en el estacionamiento del centro comercial Chedraui en San Cristóbal, autobuses a cargo de personal que labora para empresas agroindustriales en Sonora, con el fin de contratar y trasportar trabajadores de los municipios de la región Altos hasta dicho estado. Quienes ofertan trabajo se trasladan a las comunidades, también hacen uso de las radio emisoras para convocar a los posibles interesados.

En parte, estas fuerzas económicas actúan como preámbulo a la migración internacional. Pero no son ni con mucho las únicas que conducen al cometido de cruzar la frontera norte. De acuerdo con testimonios relacionados con la historia de la migración hacia Estados Unidos entre los chamulas, las primeras iniciativas aisladas se remontan hasta mediados de los ochenta de parte de algunos hombres, quienes comenzaron a abrir brecha para el desarrollo de redes migratorias aún en conformación. Algunos de ellos asumirían con el tiempo el papel de polleros, convirtiéndose así en una más de las fuerzas históricas que han impulsado e impulsan la migración hacia el norte.

En correspondencia con todo ello, el colapso de la agricultura de subsistencia significó en gran medida el imperativo para muchos chamulas de incorporarse al trabajo asalariado y a actividades informales, como la venta de artesanías y otras formas de comercio informal en diversas ciudades, lo que gradualmente los ha empujado hacia 
lugares más distantes, sin que para la mayoría ello haya significado una circunstancia decisiva en el mejoramiento de sus condiciones de vida.

Es en este contexto en el que la migración internacional ha cobrado una fuerte presencia como expectativa. Según lo insistentemente registrado mediante conversaciones informales y entrevistas individuales como grupales, realizadas entre los habitantes del municipio, la disyuntiva de migrar a Estados Unidos parte de la imposibilidad de generar los recursos para alcanzar toda una diversidad de metas. Tanto para quienes aún sobreviven precariamente del campo como para quienes lo hacen en otros ámbitos, la mayor expectativa es construir una casa de material, en muchos que sea amplia y de lujosos acabados, así como generar los medios necesarios para emprender un negocio propio. Ello implica la perspectiva de permanecer en el país del norte por periodos que van desde uno hasta cinco o seis años.

En el cometido de construir una casa, una estrategia común es enviar remesas a los familiares, con el fin de que estos se den a la tarea de conducir gradualmente la construcción. Respecto a la expectativa de iniciar algún negocio, uno de los principales medios visualizados para lograrlo es la adquisición de un vehículo automotriz y así iniciar un negocio comercial o bien de oferta de servicio de trasporte. Sin embargo, dado que migrar al norte es visto como un mecanismo tendiente a obtener sumas importantes de dinero, se habla de otras muchas metas, aunque en ello también median las circunstancias y expectativas particulares de cada persona, relacionadas por ejemplo con su sexo o edad.

Muchos hombres casados deciden migrar solos para permanecer por meses o años enviando remesas, también es posible que, perpetuando en cierto modo la lógica de cooperación de los grupos domésticos, haya padres que decidan emprender la aventura con sus hijos y así todos juntos colaborar en la empresa de generar y ahorrar dinero.

En correspondencia con lo anterior, si bien se puede hablar del incremento de cobertura educativa a escala secundaria y bachillerato dentro del municipio, se percibe una 
tendencia a la deserción escolar de los jóvenes por motivos migratorios, alentada por sus padres. El argumento que algunos padres exponen es que, a diferencia de la educación, la migración representa una opción de menor plazo para que sus hijos se integren a la vida productiva y adquieran responsabilidades en el cometido de colaborar con la economía familiar.

De manera contrastante con la expectativa de los padres, una tendencia que se expresa entre la gente joven es la búsqueda de objetivos más individuales; además de construir una casa y fundar un negocio, denotan la inquietud de experimentar poder adquisitivo para acceder a bienes de consumo diversos y a formas de esparcimiento que nutren su imaginario del norte. Se percibe en este sentido la búsqueda de aventura y de un espacio de autonomía al margen de la mirada comunitaria para vivir formas diferentes del ser joven. Entre jóvenes mujeres, esta experiencia les permite la oportunidad de establecer una relación de pareja sin que en ello medie el control familiar. Lo que conlleva empero el riesgo de aumentar el monto de la deuda contraída para pagar; en el caso de los varones, el costo de una multa por el rechazo de un cargo comunitario o el pago por la novia.

Se ha generado, por tanto, en la migración hacia Estados Unidos, un imaginario con diversos grados de fundamento que se refiere a la decisión de someterse a sacrificios, trabajos forzados y hasta sufrimientos, para en un determinado plazo dar un paso sustancial hacia el mejoramiento de las condiciones de vida.

No obstante, como la experiencia les ha mostrado, la empresa de migrar constituye para los chamulas diversos peligros, que tanto para quienes se van como para quienes se quedan representan una fuente de aprehensión. Entre estos se cuentan todos los implícitos en la travesía, ser víctimas de abusos y de delincuencia en ambos lados de la frontera, la caminata por el desierto y el peligro de morir en ella, las deportaciones, los trances de enfermedad, las consecuencias de excesos como el alcoholismo masculino, accidentes automovilísticos y riñas, los riesgos de violencia sexual en las mujeres, los 
riesgos a la salud sexual, etc. Como podrá observarse, ello participa de las emociones que nutren las experiencias del padecer.

Con su presencia, al parecer en aumento, en el país del norte, los chamulas están formando redes de apoyo e intercambio de información que se mueven de ida y vuelta entre las comunidades de origen y los núcleos en los que se agrupan allende la frontera. Se dice actualmente, por ejemplo, que quienes están de este lado se encuentran a la espera de noticias en torno a un eventual mejoramiento de la oferta de trabajo; mientras que por otra parte, se comenta que quienes sufren en Estados Unidos de los efectos de la recesión están recibiendo ayuda económica de parte de sus parientes que han regresado y consolidado con éxito alguna empresa económica.

En términos generales, se puede decir que la migración internacional produce fuertes impactos en la economía de San Juan Chamula, e inclusive en la de la región Altos de Chiapas, sino es que en todo el estado. ${ }^{1}$ El más evidente y observable es el incremento de actividades comerciales, basado en la compra de vehículos de carga que han permitido a los chamulas comerciar todo tipo de mercaderías a lo largo y ancho del municipio, así como a otros municipios de la región y más allá. Se puede hablar también del incremento, no del todo redituable por la relativamente escasa demanda, de servicios de trasporte.

Pero la migración internacional no constituye el único factor que ha dinamizado la economía del municipio y de los chamulas en general. De manera parecida, y en ocasiones interdependiente, se puede hablar de la adopción de ciertas prácticas económicas de carácter ilícito, como un fenómeno que también matiza los procesos socioculturales que los chamulas enfrentan. Son de destacar al respecto actividades como el narcomenudeo, ${ }^{2}$ el mercado negro de armas, el hurto de automóviles, la videopiratería, la tala de árboles y la comercialización de madera.

Es también de mencionar en referencia al fenómeno migratorio hacia Estados Unidos lo que he ya referido respecto a la emergencia del llamado pollerismo; es decir, todo 
cuanto tiene que ver con aquellos chamulas que se dedican a guiar migrantes, en ocasiones hasta gestionándoles empleos en los lugares destino. Esta actividad no solo contempla como clientes a los chamulas, también a otros indígenas de la región y hasta personas de diversas regiones del estado, así como a centroamericanos que han cruzado la frontera sur y cuyo destino lo constituye también el país del norte. ${ }^{3}$

En referencia a las actividades ilícitas, Freyermuth y Meneses (2008) mencionan que la autonomía de facto que se da en el municipio y entre los chamulas organizados, residentes en San Cristóbal, así como la histórica indiferencia gubernamental frente a conflictos sociales en los municipios indígenas, mayormente resueltos sin la mediación de autoridades competentes, han facilitado el involucramiento de los chamulas en actividades ilícitas. ${ }^{4}$ Es también posible sin embargo que al menos en algunos casos ello constituya una secuela de la relativa ingobernabilidad y de efectos colaterales, que en algunas zonas del estado propició el levantamiento zapatista. ${ }^{5}$

Tanto en San Juan Chamula como entre los chamulas que radican en San Cristóbal algunas de estas actividades tienden a operar bajo la lógica de negocios familiares, en los que todos los miembros del grupo doméstico colaboran. ${ }^{6}$ Esto orilla por tanto a pensar que, desde la perspectiva de los chamulas, más que un asunto de implicaciones legales y éticas se trata de una coyuntura que permite no solo la sobrevivencia, también la continuidad y hasta el mejoramiento de la vida familiar.

Es de obviar que todo ello dista de involucrar de manera exclusiva al territorio de San Juan Chamula; sus habitantes son por un lado partícipes de las dinámicas que operan en la región y, por lo tanto, los nuevos referentes que retroalimentan su vida contemplan un radio mucho más amplio; al respecto, se puede hablar de manera particular de la gran cantidad de chamulas residentes en San Cristóbal, principalmente en la colonia La Hormiga, fundada desde hace varias décadas por desplazados debido a motivos religiosos desde el propio municipio de Chamula. Hoy día, los conflictos que generaron antagonismo y hasta violencia entre chamulas conversos y tradicionalistas han ido 
quedando atrás, con lo que se puede observar que al menos en algunos casos los miembros de ambas facciones coparticipan en múltiples actividades económicas. ${ }^{7}$

Hacia el interior del municipio, también se perciben cambios en este sentido, se puede observar por ejemplo en algunas comunidades la presencia de templos no católicos, así como la aceptación dentro de la vida política local de partidos políticos diferentes al PRI, lo que no ha erradicado empero ni prácticas clientelistas a las que todos los partidos recurren en supuestos o reales contextos de pobreza, particularmente en tiempos de campaña electoral, ni al oportunismo de algunos miembros de la población para adherirse a determinadas propuestas políticas como reflejo de un pacto de conveniencia. Por consiguiente, tampoco se puede hablar de que este emergente pluralismo político constituya la expresión de una mayor apertura por parte de quienes por largo tiempo han controlado la vida política y social del municipio.

Algo que también por décadas ha tenido una fuerte presencia e impacto en la vida de los chamulas son las diversas políticas públicas emprendidas, tanto desde el ámbito estatal como federal, en aras del desarrollo y bienestar de las comunidades.

Para el caso de Los Altos de Chiapas en general, como de San Juan Chamula en particular, Rus (1995) ha documentado con sentido crítico el proceso a través del cual la relación clientelista entre el Estado mexicano y cierto tipo de líderes indígenas inició, entre cuyos efectos se cuentan las ya históricas expulsiones de grupos de conversos religiosos, a menudo, también opositores a su autoridad. Hoy día, ello se relaciona con posturas sesgadas del ejercicio de la ley que favorecen a sus adherentes, en detrimento de quienes no lo son, lo que suele verse reflejado en el manejo de conflictos interpersonales. Aunque también es posible observar sus posturas autoritarias en el otorgamiento de beneficios propios a partir de recursos institucionales y económicos relacionados con programas de asistencia social y de salud.

No se puede soslayar, empero, la relación paternalista que muchos chamulas han desarrollado con las instituciones gubernamentales, a través de la que captan diversos 
beneficios sin que se les exija una participación de mayor compromiso para el logro de los objetivos contemplados por determinados programas sociales. Sin pretender ahondar en la complejidad de esta problemática, basta señalar que al ser de corte económico muchos de los beneficios otorgados a los chamulas pueden ser también pensados como otra fuente importante de ingresos de los grupos familiares y/o domésticos, que por su parte han adoptado toda una variedad de estrategias para captarlos. En términos generales, estas se basan principalmente en múltiples formas de presentar estereotipos relacionados con su etnicidad y «pobreza», y con problemáticas particulares vinculadas con ambas categorías. Aunque en ello también participan arreglos internos entre los grupos domésticos, aquellos a menudo resultan conflictivos entre sus miembros. ${ }^{8}$

Todo lo anteriormente señalado ha conferido una particular dinámica a los procesos en los que están inmersos los chamulas, y aun de manera sutil, van delineando la transición entre lo rural y lo urbano, y por ende la convivencia entre viejos y nuevos referentes de vida, relacionados por ejemplo con las aspiraciones y con los valores sociales. Ello conlleva contradicciones y dilemas hacia el interior de la vida social, pero también elementos complementarios que operan en su reconfiguración.

De acuerdo con los hallazgos derivados de las narrativas proporcionadas por los informantes, en relación con el tema de la salud lo señalado líneas arriba no permanece ajeno a la hora ya sea de explicar la presencia de padecimientos, de buscar alternativas para recuperar la salud, de configurar novedosas etiologías, y en general de vivir las experiencias del padecimiento y demás infortunios.

\section{UNA PRIMERA MIRADA A LAS EMOCIONES}

Sin duda, cambios de índole estructural, como el gradual abandono de la agricultura de subsistencia, el deterioro ambiental y la adopción de nuevas prácticas económicas y de consumo, están teniendo un fuerte impacto en la salud de las poblaciones indígenas, incluidos los chamulas. ${ }^{9}$ Sin embargo, estos procesos también conllevan otra clase de efectos, aunque parezca difícil de creer, no del todo evidentes. Me refiero a sus 
impactos emocionales y sus consecuencias en la salud, no obstante no pretendo asumir que ello se relacione de manera exclusiva con los procesos de cambio.

Resulta difícil discernir acerca de cuáles eran las preocupaciones o problemáticas cotidianas que afectaban la salud de los chamulas en el pasado como para establecer cuáles son las tensiones viejas y las nuevas. De acuerdo con las narrativas, se identifican aspectos tales como la violencia social, la pobreza, las tensiones y conflictos, y violencias relacionadas con roles etáreos y de género que se suscitan en ámbitos domésticos y comunitarios, las disputas por tierras, los endeudamientos, las tensiones y competencias propiciadas por la estratificación social, problemáticas vinculadas a la ocupación de cargos públicos y/o religiosos, las ausencias y las adversidades causadas por la migración, las pérdidas humanas, entre las principales.

En cualquier caso, es de destacar el hecho de que todo lo anterior constituye para los informantes un referente crucial de sus emociones y su efecto detonador de diversos padecimientos que de muchas formas estaban latentes antes de su irrupción.

De acuerdo con las narrativas, en ocasiones estas emociones tienen una influencia acumulativa, mientras en otras impactan de manera abrupta la salud de las personas. Operan asimismo ya sea como desencadenantes del padecimiento o como factores que obstaculizan la recuperación de la salud.

Los siguientes segmentos ilustran parcialmente lo anterior.

El primero fue referido por la nuera de una mujer que padecía embolia, ${ }^{10}$ quien fungía como su acompañante más cercana durante el periodo en el que se realizó la entrevista $\mathrm{y}$, por tanto, mantuvo el rol de narradora durante la misma.

Cuando empezó con mucho dolor de cabeza, no sabíamos qué le estaba pasando, porque estaba bien ... Todavía no se había muerto mi suegro, fue antes su enfermedad sólo que habían muchos problemas, él era yerbero [curandero] ... No, nunca trató de curarla ... Ya tenía [dolores de cabeza cuando mi suegro vivía], hasta eso ella ya estaba mejor cuando él murió, y aparte acabó 
los problemas, y pensamos que le iba a afectar mucho cuando mi suegro murió, porque los doctores dijeron que cualquier reacción fuerte que recibiera iba a caer el doble, y gracias a Dios no, porque le dijimos «trata de olvidarlo, sabías de por sí que ha habido muchos problemas con él y ya acabó tus problemas», y así tratamos de tranquilizarla, casi no le afectó mucho.

Cuando se enfermó [ella], sí [aún vivía con su esposo], hasta eso pensamos que él iba a quedar porque él no estaba enfermo y la señora estaba grave ... Sí, entre ellos había [problemas], el señor la maltrataba y dicen que la golpeaba, todavía no estaba [yo] aquí cuando ocurría eso, y así empezó a juntar mucho coraje y hasta que cayó en esa enfermedad de la embolia, cualquier fuerte impresión ya se queda enferma ... La verdad no sé [por cuánto tiempo tuvo dolor de cabeza], como todo el tiempo discutía con mi suegro, no nos dimos cuenta y no decía si estaba enferma, sólo se veía que estaba mal y ahí la dábamos a curar [con iloles] ${ }^{11}$ y sí se le pasaba, y así pasó un día que estaba lavando en el lavadero, se quedó detenida y cayó de una vez ahí.

En una vena similar se expresa otra mujer, que padecía de hipertensión arterial, y para quien su condición de poliginia ${ }^{12}$ constituía la fuente y origen de sus males:

Solo pensé que se me iba a pasar, «¿será que es una enfermedad?», dije nomás, y así pasó el tiempo, pero lo que digo donde empezó mi enfermedad es por tristezas y cólicos.

Sí, fue con mi esposo, y por todas las cosas que han pasado, no sé si has sabido de que somos muchas mujeres. ${ }^{13}$ Sí, es por eso, y siento que es ahí donde me empezó mi enfermedad. Somos muchas [esposas] ... yo soy la primera, y es por eso que recibí mucho coraje cuando se juntaron, y ahí poco a poco empezó mi enfermedad.

Los anteriores segmentos aluden a aspectos como la violencia conyugal y a las inequidades de género que tradicionalmente han existido en San Juan Chamula, pero como he anticipado, las tensiones que afectan la salud tienen también que ver con el impacto de los procesos de cambio que los chamulas experimentan en la actualidad.

Una muestra de ello resultan las palabras de una mujer con diabetes, que habiendo sufrido la pérdida de su esposo, quien fue asesinado, y la de un hijo que murió intentando cruzar la frontera con Estados Unidos, refiere la muerte de otro de sus hijos en San Cristóbal mientras trabajaba, por picaduras de abejas, como el evento detonante. 
Ya tiene más de un año mi diabetes, y de mis brazos que me duelen mucho, me enfermé porque lloré bastante, puro llorar hacía, no comía nada, estaba yo muy triste, aguanté como tres semanas en no comer ... desde que se murió mi hijo, ya salió como tres años.

Sí, fue ahí donde me enfermé mucho, ya nadie me da dinero porque él me daba, me mantenía y todo, sentí mucho la muerte de mi hijo, hasta ahora no me he recuperado [de tristeza llora la señora], ya no tengo a mis hijos que me daban dinero, cada que venía de su trabajo me traía mi comida, mi azúcar, mi jabón y me daba mi dinero, es por eso que me enfermé mucho cuando lo perdí porque ya no hay nadie quien me da dinero, ahorita me siento muy mal, no hay quien me compra mi ropa ni mi chal, voy a estar desnuda ya, no tengo nada que agarrar, fue ahí que me enfermé mucho, lo sentí, me empezó a doler el pecho, sentía que algo se me subía, es como si fuera una bola, me daba unos dolores que no se podía aguantar, mis brazos, mi cabeza me empezó a doler, me dejaba muy mareada...

Como he anticipado, las problemáticas que afectan las emociones también inciden en la imposibilidad de recuperar la salud y aun como factores que tienden a agudizar los padecimientos.

Es interesante asimismo observar que las situaciones sociales que generan conflicto y tensión se nutren tanto de viejos como de nuevos referentes que pueden interactuar de manera conflictiva en detrimento de la salud. El siguiente testimonio de una mujer que padecía diversas dolencias ilustra esta idea.

...me he sentido mal porque a veces llegan los dueños de nuestra deuda, y entonces me pongo muy mal porque no les podemos dar nada ... porque me han dicho que cuando se pone uno mucho a pensar se enferma uno, antes sí me preocupaba mucho, y estoy pensando si es por eso, porque muchas personas me han dicho que así hace cuando uno piensa mucho, y si uno se preocupa mucho, incluso hasta hacer mucho coraje, nos enferma como dicen, por eso ya pienso que sí me enfermé por eso, todo por hacer mucho coraje, la preocupación, y las tristezas, ahora tengo este dolor de los pies, de las manos y de la espalda. ¿Será que así nos hace? ... Eso me dijo una persona que vive hasta allá ... «Yo creo que sí [es $i l o l]^{14}$ porque también nos pone velas ... es en San Cristóbal», y así me dijo: «Es que te preocupas mucho, por eso ya estás enferma»; «Sí, porque tenemos mucha deuda», le dije. «Pero de qué te sirve estar enferma si no solucionas 
nada, mejor ten fe y esperanza de que todo te saldrá bien, de las preocupaciones ya tienes esos dolores de tu cuerpo», me dijo.

...[mi esposo] no tiene dinero, yo sola me visto, es porque tenemos deudas y él lo está viendo, y más que tuvo problemas, le afectó mucho. Él tuvo problemas por ser pollero, como ya lo mencioné, y otra más, hace como un mes, que fue el mes de septiembre, sólo por acompañar a su hijastra en la presidencia de aquí en Chamula, le dieron un cargo de mayordomo de la virgen del Rosario, este cargo le dieron sólo por haber defendido a una muchacha que la estaban obligando a casarse con un muchacho que ella no quería, la muchacha era como criada de su hijastra, por eso llegó a defenderla, las autoridades no les pareció, entonces por coraje lo metieron en la cárcel y después le dieron ese cargo para un año, nos sentimos mal porque no teníamos nada que ver con ese problema que hubo, no pensamos pasar ese cargo, aunque nos van a pedir la multa de seis mil pesos...

De igual modo, dado que las problemáticas vividas por los chamulas también se enmarcan dentro de procesos sociales de mayor amplitud, como la migración, igualmente constituyen una fuente de tensiones y aprensiones. El siguiente extracto testimonial de una mujer con diabetes da muestra fehaciente de ello:

...[mi hijo] no está estudiando, él se fue a buscar trabajo, pero se fue en vano porque no tiene un buen trabajo, él está sufriendo ... Sí, está lejos, pero se fue en vano, está sufriendo, y también por él me preocupo, porque no muy está bien, le sale sangre en la nariz ... Sí, está enfermo, no está bien, le sale sangre en la nariz, casi seguido le pasa eso, y es por eso que también me hace preocupar, me da lástima porque casi no muy come en donde está, hasta eso su papá le manda dinero, porque no tiene trabajo.

Parece que no [por eso que empieza la enfermedad], porque me han dicho que no me preocupe, que porque me podría empeorar del azúcar, pero como digo sólo Dios sabe si me voy a empeorar, porque qué le voy a hacer si extraño mi hijo, digo nomás...

Ya no, no me acuerdo qué mes fue que habló, diciendo que está mal y que ya tenía más de una hora que le estaba saliendo la sangre en la nariz. «Ya te dije te regresaras, o quieres morirte lejos así como muchos se regresan muertos, ahora dónde voy a buscar ilol», le dije, y estaba llorando que no se le paraba la sangre, eso le tuvo miedo, como fue en la noche, entonces salimos a buscarle un ilol, y le puso su vela luego, yo creo que sí le valió, ya después no sé qué pasó, ya no ha hablado, a lo mejor se le terminó su dinero, porque ya no ha hablado, hasta ahora nada... 
Por lo dicho hasta aquí respecto al rol de las emociones, es claro que el vínculo que estas tienen con los problemas de salud y con las condiciones de vida da cuenta de un enorme vacío que las políticas institucionales en salud no logran siquiera visualizar.

\section{LA RELACIÓN DE LOS CHAMULAS CON OTRAS MEDICINAS}

A través de algunos testimoniales presentados hasta ahora, es posible entrever que la consulta con iloles, ${ }^{15}$ así como con otros terapeutas populares fuera del municipio, es un referente crucial para atender los problemas de salud y demás adversidades.

De acuerdo con algunos testimonios, la consulta con iloles expresa una expectativa de tipo emocional en torno al padecimiento que se sufre, aunque ello no cancela la posibilidad de que también se esté buscando atender dolencias corporales.

Pero el apego a ellos no significa que necesariamente se relacione con expectativas no satisfechas respecto al uso de la biomedicina. Es una realidad observable desde muchos ángulos, el fuerte apego que los chamulas mantienen para con las formas propias de atender sus problemas de salud; apego que persiste aún ante la creciente cobertura de servicios institucionales de salud a escala local. Pero esto no significa que los propios chamulas no interactúen con ellos y que incluso no se hayan apropiado de algunos preceptos de la biomedicina, no solo a partir de la acción institucional, también de la interacción que han mantenido y mantienen con otros referentes biomédicos.

Se puede observar, por ejemplo, la presencia de un imaginario que los chamulas y otros grupos indígenas de la región han históricamente construido en torno a los medicamentos de patente, desde que en Los Altos de Chiapas se comenzaron a ejecutar las primeras acciones institucionales de atención a la salud. Aunque en la literatura especializada se hace referencia a algunos datos sugerentes (Holland 1962, Harman 1969, Köhler 1975, Freyermuth 1993), no se ha realizado hasta la fecha un estudio que de modo particular profundice y amplíe este tema. 
Este imaginario constituye un referente básico a la hora de juzgar qué instancias biomédicas proporcionan o no una buena atención o medicamentos, sin olvidar que también ha sido partícipe de cierto nivel de apropiación de diversos preceptos y prácticas de atención, por lo menos parcialmente relacionados con la biomedicina, que son importantes de considerar.

Se pueden mencionar, por ejemplo, las opciones de atención a la salud con que cuentan los chamulas, además de las que pueden ser juzgadas como propias. Entre estas se incluyen aquellas con las que tienen contacto tanto dentro como fuera del municipio. Algo digno de destacar al respecto es que al interaccionar con esta multiplicidad de opciones los chamulas dialogan con diversas lógicas que continuamente se traslapan, no solo porque en dicha interacción confluyen conocimientos y representaciones muy diversos en torno a la salud y a la enfermedad, sino porque también los chamulas los articulan a través de sus propias experiencias del padecer.

Las narrativas dan cuenta de la compra de medicamentos en farmacias, tanto dentro como fuera del municipio.

Es también posible observar en la cabecera municipal los domingos a vendedores de hierbas medicinales, quienes las ofertan para el tratamiento de diversos padecimientos, entre los que se incluye la diabetes, de significativa presencia entre los informantes, ${ }^{16} \mathrm{o}$ bien puestos de medicina naturista ofertando con altavoces el nombre en tsotsil de medicamentos y de las enfermedades para las que son útiles, e inclusive de productos Omnilife. En cualquier caso, estos puestos suelen atraer una numerosa audiencia de potenciales y reales compradores.

El papel de las redes de información y en ocasiones de apoyo con que cuentan los chamulas lleva a que en los testimoniales se hable de preparados de plantas recomendados y comprados, en ocasiones por encargo, para tratar diversos males. En ciertos casos, los informantes han comenzado a cultivar plantas medicinales provenientes de otras zonas. 
También acceden a estos recursos en San Cristóbal, donde utilizan además servicios privados de salud, sin que se pueda dejar de considerar el trato con diversos tipos de curanderos que también se encuentran en San Cristóbal y en otros municipios; entre estos destacan los espiritistas. Hay quienes, incluso, habiendo cambiado o estando en la disyuntiva de cambiar de religión, se dirigen a la ciudad para atender sesiones de culto, a través de las cuales también suelen atender sus problemas de salud. Si bien la influencia de las redes de información es relevante en todo ello, existe también una lógica que guía el uso alternativo, secuencial, o indistinto de estas opciones, en la que participa preponderantemente la propia experiencia del padecer de cada persona.

\section{EL DIÁLOGO CON EL CUERPO}

Así, la búsqueda de atención está parcialmente mediada por un diálogo entre la persona y las reacciones que su cuerpo va manifestando en torno a los efectos derivados de determinados medicamentos o tratamientos, sean biomédicos o de otro tipo. En ello intervienen síntomas percibidos de mejoría o de agravamiento o de efectos colaterales, con frecuencia interpretados en el marco de referentes como el de la dualidad frío/calor. Es de destacar respecto a las percepciones en torno a las reacciones del cuerpo, que estas se manifiestan fuertemente asociadas a su capacidad de mantener su funcionalidad, es decir, de hacerse cargo de las faenas cotidianas, por pesadas que se sugieran.

Esta clase de diálogo suele articularse con una trayectoria de búsqueda de atención que da cuenta de una gran diversidad de opciones que incluyen remedios, medicamentos y distintos actores relacionados con la atención a la salud.

Vayamos ahora a lo que las narrativas nos dicen al respecto:

La siguiente fue referida por un hombre que tenía problemas para discernir el carácter del mal que le aquejaba, el cual inició al momento en el que se le derramó diesel en el abdomen. Dado que una de los primeros signos fue la presencia de granos en dicha zona del cuerpo, él se aplicó tabaco mezclado con pox [aguardiente]. Como veremos, su experiencia constituye un ejemplo por demás impactante de dicho diálogo. 
No es igual [que si me quemara], este me pica, parece que sintiera frío, si me empieza fuerte me da un poco de diarrea, y como ya entró de mi estómago busqué la Pemprosilina, que fueron seis Pemprosilina y dos Penicilina ... No [me lo recetaron], sólo lo busqué, lo compré yo, con eso se quitó un poco el dolor, nada más fue como calmante.

Es inyectado, después llegó un compañero que sabe de medicina, se enteró que estoy mal ... le empecé a explicar cómo estuvo, que con el diésel empezó mi enfermedad; «tengo la medicina y si no te curas te va empezar el cáncer y te vas a morir, mejor compra tu medicina», me dijo, y así lo compré, hasta me dejó fiado la medicina, me dejó como tratamiento, hay inyección, tomado y en cápsulas, así terminó el tratamiento y no hizo efecto. Llegó otra vez, que fue la segunda vez, y llevó consigo su termómetro que era para ver la enfermedad, y me dijo que faltaba más medicina para curarme, tres inyecciones más y treinta cápsulas. «Bueno», le dije, y gasté trescientos cuarenta pesos, y de ahí con el segundo tratamiento me hizo mal las medicinas.

Lo que pasa es que fui de visita en otra casa de ahí en mi comunidad, esa mañana había recibido la inyección y al medio día tomé un refresco, comí pollo de rancho y carne de res sin nada de verduras; ahí descompuse mi medicina, esa noche no pude dormir, me dio insomnio desde la fecha hasta hoy, sólo que ahora tomo pastillas, el doctor me dio, así puedo dormir, aguanté un mes y diez días sin dormir, hasta me dio cuatro ataques cuando estoy acostado ... como si viniera ya mi sueño pero no, es que mi corazón ya se va a parar, mi cerebro, mi sangre ya estaban muy cansados porque trabajan día y noche ... hasta pregunté en la farmacia si había un especialista, me dijeron que sí y me fui rápido a buscar, y sí encontré al doctor pero me regañó: «¿por qué te vas a matar?, ¿por qué vas a comprar medicina en la calle?», me dijo... [era] de San Cristóbal, es particular: «estás joven, te van a matar», me dijo. Y así les dijo también a mis dos hijas, me dio unas pastillas que es el Dibotril, todavía lo estoy tomando; si tomo esta noche ya sería hasta el tercer o cuarto día, porque está muy fuerte.

Ya lo suspendí [todo lo demás], nada más que ahorita estoy tomando unas vitaminas porque me volví a ir al doctor pero ya con otro, es que me debilité, como soy autoridad tengo que aguantar muy temprano, mi cargo es mayol, no es igual que oficial, en cualquier hora llega una orden para ir a traer personas, no hay horario para descansar ni en la noche, es por eso que fui con otro doctor para recibir mi vitamina, pero tampoco la vitamina me hace bien, calienta todo mi cuerpo. Del dolor sí [me sigue molestando], a veces como ahorita está calmado, pero ayer me estuvo doliendo, a veces está calmado unas horas y después vuelve lo mismo, así que ya tengo dos enfermedades, principalmente en mi estómago y luego en mi cabeza, pero causado por las medicinas que tomaba. 
Sí [por falta de sueño], pero cuando estaba bien dormía bien, aunque me tomaba dos refrescos o dos tazas de café, nomás me acostaba entraba luego mi sueño en la noche, hasta que encontré la desgracia.

Un poco [estoy del sueño], porque tengo las pastillas para que duerma, cuando como pollo me calienta mi cabeza, aunque sea cualquier comida, ya sea verdura o frijol, y si está caliente me hace mal, se calienta mi cabeza.

Sí, me revisaron con el ultrasonido [mi estómago], yo no le dije que cuando comía cosas calientes me hacía mal, ese no le dije todavía, nada más le dije que tenía dolor y me revisaron con el ultrasonido, me dijo que no tenía nada, que estaba yo sano.

...sólo le explique como se lo expliqué a usted, que me empezó con el diésel, pero me dijo que con el diésel no pasa nada, que no da enfermedad, y que es otra enfermedad lo que tengo ... Del dolor del estómago sí, sólo me dieron unas pastillas ... ya no me acuerdo [cómo se llaman], allá quedó en San Cristóbal, pero no me hizo efecto ... El mes de noviembre lo tomé, hubo unas que sí me hizo efecto, me las recetó un señor y traía sólo cuatro pastillas, no me acuerdo cómo se llaman, me dijo que era para dolor, y sí me hizo efecto, se calmó un poco; entré de ser comité y ahí tomé refresco y nuevamente volvió el dolor, ya no volví a comprar esa pastilla. Sí, no que busqué otro, fue inyección y de ahí me hizo mal de una vez, me equivoque y ya perdí.

Ahorita estoy tomando pastillas para poder dormir, pero siento que está dañando mi espalda... [se llama] Ribotril, «está muy fuerte», me dijeron, había otro menos fuerte pero no me hacía entrar el sueño para nada, sólo Ribotril me deja dormir.

Aunque esté tranquilo, mi cerebro no sé dónde está, tal vez está alterado mi nervio.

Para mi estómago nada [estoy tomando], estoy apenado porque parece que quiere algo caliente, como que está frío del dolor, cuando todavía no había tomado ninguna medicina sentía que estaba muy frío mi estómago, sentí que avanzó el frío cuando comí pescado y como es frío el pescado... O sea, que avanzó más cuando comí pescado, parece frío, como ya le había mencionado, hice mi remedio, herví el tabaco junto con el pox y lo unté en mi estómago, como es caliente calmó el dolor que sentía... Sí, también el dolor que sentía adentro, no tengo temascal para bañarme, sólo así calentando mi agua, pero cuando me baño en la mañana se siente el frío y avanza, parece que la enfermedad es frío, estoy preocupado por mi cabeza porque no quiere nada caliente y mi estómago quiere caliente. 
Como también puede corroborarse, dentro de esta lógica parece tener plena cabida la relación que la gente establece con las farmacias y los productos que ofertan. Estas constituyen, sin duda, también un lugar de consejería médica, en la que los propios encargados de atender a los clientes prescriben, aun con un marco de referencia biomédico aunque con sus particulares puntos de vista, de acuerdo con los signos y síntomas reportados por sus clientes.

Una dificultad que se observa respecto al diálogo que los chamulas mantienen con los representantes de la biomedicina radica en el hecho de que mientras estos últimos definen algunos padecimientos en términos de un complejo de síntomas y/o dolencias, para los primeros cada uno de ellos representa un problema específico a ser tratado, también por un medicamento específico.

De ello da cuenta una mujer que había sido diagnosticada en el centro de salud local con hipertensión arterial; al sentirse insatisfecha y hasta afectada negativamente por la medicación que allí llevaba, decidió recurrir a otros medios para tratarse el dolor de su pie, acerca del cual el médico le había asegurado ser consecuencia del mismo mal:

Todo ha sido el Captopril, compré la otra vez pero ya le tiré la cajita ... no, era diferente [a la que me dio el doctor], en cambio el Captopril siempre ha sido eso que me dan cada mes en la clínica ... no le vale bien y eso que cada mes lo estoy tomando, si le valiera yo digo que ya le hubiera sentido el efecto, y me han dicho que si lo llegara a dejar de tomar me moriría luego. Así me dijo el doctor: «si lo llegas a dejar de tomar las pastillas se te va subir la presión y te puede matar luego», [cuando se me sube la presión] es mi corazón que me empieza a doler, no me deja caminar, una vez que caminé luego se me tapa el pecho, es como si me tapara el aire que respiro. También en mi pie que me empieza a doler mucho, sólo porque busqué mi remedio fui en la farmacia a preguntar si tenían remedio para mi pie, y les dije cómo era el dolor, le dije si era ácido úrico lo que tenía, porque me dolía mucho el pie; así le dije a Chelo, dueño de la farmacia: «yo creo que sí es lo que tienes», y me dio mi medicina, pero un poco que le valió, para nada ... recibí inyección y también tomé pastillas ... No me acuerdo [del nombre de las medicinas]. Sí. ahí me dieron en la farmacia, pero sí busqué mi medicina, quizás fue sólo un poco que le valió, ahora ya está en mis manos los dolores ... Ya solo un poco [siento dolor en los pies], en donde lo siento es en la mera rodilla, es como si fueran espinas que me están picando. 
Sí, le dije [al doctor que me dolían los pies], y le dije que había comprado mi medicina ... [me preguntó] «si te acuerdas del nombre de la medicina que compraste, es mejor que compres más», pero no le dije de lo que me dan cada mes, sólo lo de mi pie, así es como volví a comprar, y una inyección me costó \$200 pesos, con eso me dejó caminar, porque ya no podía caminar para nada, así como me hinco para tejer no podía hincarme, no podía trabajar para nada. Solo una inyección recibí y es lo que me costó \$200 pesos, y después recibí cinco inyecciones, así me he estado atendiendo, y como que eso le valió pero ya con puras medicinas compradas ... las pastillas que me dieron y que me siguen dando en la clínica es la que dejé de tomar, porque vi que no le valía para nada, ya sólo tomo las que compro.

Yo creo que ya tiene como tres meses [que las dejé de tomar], «¿todavía lo sigues tomando?», me dijo el doctor, y me dijo que subí de peso, que llegué a pesar de 68 kilos, que es mucho lo que tengo, así me dijeron, pero cuando dejé de tomar las pastillas que me daban allá y empecé a tomar las que estuve comprando fue que bajé un poco de peso, así como dice el doctor que bajé kilo y medio, pero por las pastillas que compré.

Sí, eso le valió, hasta eso ya se estabilizó mi presión, así me dijo el doctor cuando me volvieron a checar, pero gracias a las medicinas que compré le valió.

Sí, a \$200, la otra de cinco inyecciones parece que me costó \$90 pesos, y aparte las pastillas ... no me acuerdo cómo se llama, sólo llegué a preguntar en la farmacia, como ya no podía caminar, llegué a preguntar qué me podían dar para esos dolores...

La verdad no sé [si es ácido úrico], pero como no me sacaron la sangre para analizarlo, así que no sé si es; sí, me sacaron pero no apareció esa enfermedad, yo digo que hubiera salido en el análisis, cuando me vieron de la presión.

...Sí la compré todavía, me dijeron que también hay tomado [preparado de hierbas], y también lo compré ... Como que sí le vale, ya no me tapa tanto el pecho cuando camino, porque si lo siento, así como cuando voy a buscar mi leña ya siento que sí puedo, por eso que estoy tomando esa medicina, puras plantas preparadas.

No [se consigue aquí], esas me las compran en San Cristóbal ... como que le vale mi enfermedad que tengo ... Ya [viene preparado], es que me vio una persona y me dijo que sí había remedio para esta enfermedad que tengo, y me dijo que sólo en San Cristóbal se conseguía, le pedí favor que me lo consiguiera, y me lo fue a comprar. 
Es de suponer también, que la introducción, al menos parcialmente exitosa, de productos como Omnilife, dado que incluyen suplementos alimenticios y vitamínicos, y por los efectos a corto y mediano plazo que ejercen sobre los enfermos, responde a esta misma lógica. Para quienes pueden solventar su costo, su uso también resulta un referente en los procesos de búsqueda de salud. ${ }^{17}$

El siguiente segmento da cuenta parcial de las estrategias que la familia de la mujer diagnosticada con embolia estaba adoptando para tratarla. En este caso, un hijo de ella trabajaba para la empresa.

Ya tiene como un mes que no se ha debilitado, es que había dejado de tomar su suplemento y le volvimos a dar y ya es cuando está más o menos ... se debilita [si lo deja de tomar], como que no tiene mucha energía ... Un poco [caro], le estamos dando un producto que se llama Omniplus, y Optimus, es líquido porque casi no todo le cae bien, le da dolor de estómago, y con esos dos productos es la que no le hace mucho daño.

El siguiente segmento, alusivo a un hombre con diabetes, presenta una faceta adicional en relación con el componente de la búsqueda de atención que yo identifico como el diálogo con el cuerpo. Llama la atención lo problemático que puede ser para los hombres el consumo de alcohol para manejar un problema de salud.

Sí, me hizo estudios de sangre, y me dio unas cápsulas, pero no quise ... porque me dijo que no podía comer: «apenas tres tortillas vas a comer o tostadas», así me dijo, y eso no me gustó; «mejor voy a curarme entonces, ya sé que es azúcar», y movilicé de qué hierbas puedo tomar. Me dijeron por el doctor: «bueno, si no te gusta ese mejor ya déjalo».

...bueno, ahorita ya no [sigo tomando yerbas], porque ya se me quitó ... sí, bueno cuando me enojo a veces me sube, no sé cómo me seca luego los labios ... sí, porque una cosita, más se viene que no se cumpla ... se seca luego la boca.

...pero la sed ya se me quitó el agua, ya se me quitó el refresco, ya todo ... Tomo pero ya sólo uno o dos, nada más, pero antes tomaba doce o puro jumbo pero frío. 
Estuve casi nada más que... un mes [tomando plantas], luego me quitó ... ya no [me siento mal], solo hay veces que tomo el limón, así se me quita. Sí, a veces [se me quita con puro limón] ... así nomás lo exprimo y lo chupo...

¡Ah, sí!, [cuando me enojo] luego se pone débil uno, el cuerpo se pone débil luego, a veces da sueño luego.

...Bueno, a veces me quita y a veces no [con las hierbas]. [Cuando no se me quita] Por eso me echo mi copita de pox.

...Ahorita no tiene días [que mi esposa me curó con velas] ${ }^{18}$, como una semana ... bueno, no tanto así [que me cure cada semana], según la enfermedad, si me debilito después me ponen la vela..., si cada que tengo debilitado el cuerpo.

Me hace daño a veces que me... me empieza dolor acá en mi pierna ... parece como... ácido úrico... [me lo curo] con pomadas. hay veces le pongo ... nomás le echo una pomadita, de bálsamo o Vaporrub, nada más así se me calma ... Un mi amigo, sí [me aconsejó el Vaporrub].

Cuando tomo cerveza me empieza a doler ... bueno sí, a veces que ... cuando trabajo, es que a veces que cuando salgo le echan chile la comida, porque a veces que no se puede comer chile, ni refresco así. Tengo mi tratamiento ... De bálsamo, sí... Sólo eso [me da] nada más [dolor de pierna].

Ah, bueno, cuando ya tomo trago empieza dolor de la cintura... me duele a la hora de parar, ya no se puede parar uno, sí... le pongo algo, la pomada [cuando duele].

...Sí, la misma pomada. Sí, pues [me envuelvo la espalda], para que no le entre frío.

Mi esposa, primero me talla y después de ahí...

...Bueno, ya empecé a tomar ... a veces sí, de jabil [el cargo que tengo] —quien se ocupa de servir el pox, pero tiene que servirle a un mayordomo_-... Sí, es el último que tomé [en la última fiesta], casi una semana, nunca me ha pasado así... ¡ah, sí!, me quedé débil y un poquito mal...

...fui a comprar mi medicamento ya, ya sentí ya, por la cruda me está matando, mejor fui a la clínica. En Zinacantán... con Manuel, sí me dio un jarabe, pero no sé cómo se llama el jarabe... 
Sí lo tengo, ahorita estoy tomando, por eso no tomo refresco, ni pox ni chile... nomás que termine un frasco y que tengo que aguantar dos meses todavía, sí... me explicó que ya no tome, porque si tomo va ser lo mismo otra vez que tomo el pox. Con ese trago sí, bastante [peligroso que tome jarabe]; es que una vez así compré un jarabe que viene de Guatemala y no tomé, a la hora que tomé fue cuando estaba tomado, al amanecer era para morirse ya... no lo estaba tomando, nomás que de locura lo tomé cuando estaba yo tomado... y al amanecer sentía morir... dolor, bastante, pero con la coca se me quito, fría... me hizo reaccionar, me recuperó.

...es que viene a vender un ambulante... de Guatemala.

Ese no [no era para el azú]car), es que nomás era para mi cerebro, es que estaba perdiendo la vista... Sí, para la vista, para que me recupere... Sí, me nublaba [la vista] y después cuando lo veo así ya no veo tan lejos, y a veces los hombres que ya no los conozco. Sí... bueno sí, tengo problema ahorita por la vista, sí.

Cuando tomo a veces así me pasa, pero ahorita sí y lo veo así nomás que me tapa; Sí me tapa un poquito... sí se me tapa, es más peor [cuando tomo].

Tengo todavía el frasco ahí, no lo he terminado... Así se llama Cerebral... Yo creo que sí está hecho de hierbas como uva, ahí se ve en el frasco ... ya no lo tomé porque ya pasó, pues, porque ya tiene como más de dos años parece que lo compré ... porque no trae cuando vence, por eso ya no lo tomé.

Con todos los temas anteriores en mente, se puede observar en las narrativas una miríada de posibilidades que permite asumir que a lo largo de un proceso de búsqueda de atención ninguna opción, pese al antagonismo formal entre algunas de ellas, excluye por fuerza a la otra, y ninguna es tampoco en definitiva desechada. Todo ello tiene que ver con la trayectoria de la propia persona enferma, lo que involucra el curso de su padecimiento, así como eventos conectados o colaterales al mismo.

Pero más allá de la multiplicidad de posibilidades de la que da cuenta éste que yo llamo el diálogo con el cuerpo, es pertinente también abordar un campo de reflexión en torno a lo que propongo como una dimensión más íntima y a la vez dramáticamente social, de la experiencia del padecer y el infortunio, que también incide de manera relevante en las trayectorias de búsqueda de atención. 
Pero más que describir el carácter de estas concepciones y prácticas per se, mi cometido es explorar sus inagotables posibilidades al ser articuladas con las experiencias personales del padecimiento y el infortunio.

Además de buscar tratar las dolencias emocionales y del cuerpo, lo que invariablemente subyace en la consulta de un ilol es el cometido de identificar, contrarrestar y/o erradicar las causas del padecimiento y el infortunio. En este sentido, son de destacar algunos conceptos recurrentemente reportados por la mayoría de los informantes como causas de sus padeceres.

Estos son: komel, potzlom, ilbajinel y chonel, términos todos ellos en los que muchos, sino es que todos, los síntomas o padecimientos descritos por los enfermos tienen cabida; ya sea como su manifestación parcial o total, independientemente de que existan o no diagnósticos y tratamientos biomédicos. Sobre ello volveré con mayor detalle.

\section{LA ARTICULACIÓN NARRATIVA DEL COMPLEJO ENFERMEDAD/INFORTUNIO}

De manera regular, en mayor o menor grado, los chamulas que han narrado la experiencia de sus padecimientos se refieren a éstos en relación directa o indirecta con otros eventos adversos que parecen matizar el curso de historia personal y de su vida cotidiana Es de destacar al respecto que, tanto los padecimientos como otras adversidades que se han vivido y se viven, pueden ser vinculados directamente con el padecimiento que en un determinado momento los informantes describen como el principal motivo de su propia narración.

De acuerdo con ello, es posible que dicha experiencia participe de una serie de adversidades articulada en la narrativa, cuyo marco explicativo nos dice mucho acerca de la vida social de la persona enferma, así como de la de su grupo familiar y demás allegados, en particular de las percepciones que cualquiera de ellos mantienen en torno a la misma. Dentro de esta lógica, las demás adversidades referidas no son 
necesariamente situaciones directamente vinculadas a la persona enferma, sino a cualquiera de sus familiares u otros miembros de su red social.

En otros trabajos (Eroza 2006a, 2006b, 2008) me he referido a estos casos como experiencias compartidas de enfermedad/infortunio. Ello en parte significa que en lo que atañe a este contexto hablamos de una ponderación sociocultural de la persona plenamente articulada en un colectivo, tanto familiar como comunitario, en la que se expresa una clara correspondencia entre actos y consecuencias que de manera recíproca, desde el marco de determinados valores, pueden responsabilizar y afectar a todos y cada uno de los miembros de dicho colectivo.

A través de las experiencias narradas se puede observar cómo precisamente las visiones locales de la persona se ven recurrentemente y de muchas formas confrontadas en un contexto en el que nuevos referentes de vida se han venido posicionando. Ello hace del padecimiento y del infortunio un rico lenguaje simbólico de la vida social tal y como tiende a ser vista y experimentada por los chamulas. Esto último no significa empero que tales nociones se vean confrontadas sólo en referencia a lo nuevo; la rigidez que de sí denotan parece mantener una brecha permanente, a menudo tensa, entre las aspiraciones promovidas por la tradición y lo que las vidas vividas revelan.

En lo que concierne a las narrativas del padecimiento, todo ello se relaciona con las visiones locales acerca de las causas que originan y perpetúan la presencia de la enfermedad/infortunio.

\section{CAUSALIDAD, VARIACIONES SOBRE UN MISMO TEMA}

Las ideas causativas locales se basan en parte en conceptos relativos al castigo divino, la brujería y a concepciones espirituales; y en parte, en valores sociales vinculados a las aspiraciones culturales, y a la forma en que los individuos se posicionan frente a todo ello, pero también de acuerdo con las valoraciones en torno a nuevos referentes. Lo que quiere decir que las personas no experimentan sus concepciones culturales como representaciones uniformes y estáticas, sino como recursos de gran plasticidad que les 
permiten más que establecer de manera concluyente la explicación de sus experiencias, resignificarlas continuamente de acuerdo con el acontecer de sus vidas. Es pertinente agregar que en tales experiencias, el campo de lo onírico juega un papel crucial.

En su mayoría, las narrativas dan cuenta de historias en las que, dada la indefinición con que son presentados los padecimientos, la incertidumbre aparece como una constante y un hilo conductor para especular acerca de inagotables posibilidades. Opera, entonces, como un amplio marco de referencia que da cabida a toda suerte de conjeturas a la hora de buscar explicaciones en torno a la enfermedad y al infortunio.

Ello implica, por ejemplo, que las causas asignadas al padecimiento y al infortunio varíen o se alternen de muchas formas a lo largo de una narración, pues en ello median la dimensión del tiempo y, por supuesto, los eventos que acompañan a lo largo del mismo a las experiencias referidas.

Así, es posible que una primera explicación causal ceda su lugar a otra, o que ambas se vayan sumando a otras, o bien que cada una o todas juntas se enriquezcan con nuevos elementos, gradualmente incorporados a la lógica narrativa. En la medida que todo ello ocurre, es también posible que el número de personas involucradas, en un sentido u otro, en las experiencias de enfermedad/infortunio se incremente.

Como he mencionado, estas ideas suelen ser asociadas a categorías como komel, potzlom, ilbajinel, chonel, y algunas más. En teoría al menos todos ellas se refieren a distintos eventos causativos.

Expongo aquí algunas definiciones de las mismas, proporcionadas por una mujer ilol.

...Son los espíritus de las malas personas que vienen a molestar en la casa, por eso soñamos cosas malas, llegan a espantar en el techo de la casa haciendo ruidos o cuando uno está dormido empieza a brincar a gritar, esa es ilbajinel. 
El otro es chonel, es cuando la persona nos quiere ver muertos y nos venden en las cuevas, en los panteones, en los ríos, o en donde quieran.

La otra es el komel [espanto], que existen dos tipos de komel, la primera es cuando nuestro espíritu lo tiran y se enferma uno de repente, ${ }^{19}$ y la segunda es cuando el espíritu se queda atrapado donde se cae uno, por lo mismo que está muy viva la tierra.

La otra es potzlom, es cuando nos meten diferentes cosas en el estómago, pero así sólo llega, porque así lo deseó la mala persona, como a mí me metieron semillas de naranja en mi garganta y ahí creció, hasta eso empezó a salir las hojitas en mi nariz, le pedí mucho a Dios y lo expulsé por medio de la tos y flemas; el puño de tierra que apareció en mi estómago, pues así desapareció hasta que le pedí igual a Dios.

La otra es ti'olal o sbiktal kontontik [corajes], es cuando entre parejas nos regañamos, igual se tiene que poner velas para pedir perdón, porque se enferma uno o los niños se enferman. Son como siete u ocho curaciones que se hacen.

$\mathrm{Si}$ bien para la mujer que dio estas definiciones, las categorías cuentan con demarcaciones muy precisas, mediante un vistazo a las experiencias narradas por los enfermos es posible observar que no se trata de concepciones del todo homogéneas. En gran medida éstas se encuentran moduladas por las propias experiencias.

Por ejemplo, varias mujeres dieron cuenta del potzlom como la intrusión, mediante sueños, de sustancias de calidad fría, que en gran medida explicaban la naturaleza de los síntomas o padecimientos que experimentaban. No obstante, por el carácter particular de sus trayectorias, se puede deducir que ello está vinculado a las condiciones desventajosas que como mujeres enfrentaron en diversas etapas de sus vidas y que aún enfrentaban. Significativamente, un sueño referido por más de una fue el de haber sido violadas. En gran medida ello se expresa como un reflejo de sus miedos cotidianos, que no suelen carecer de fundamento.

Un ejemplo es el expuesto por la mujer que situó el origen de su diabetes, de frialdad de matriz y de sus dolores de músculos y huesos, en un periodo en el que padecía de la 
violencia de su primer esposo ya fallecido. Al explicar lo que para ella era el potzlom, refirió los siguientes sueños.

Eso dicen, si vemos que nos violan o ya sea nuestro marido es cuando nos enfermamos, deja su frialdad en nuestro estómago, pero no sé en qué momento lo soñé cuando me enfermé, hasta he soñado que abrazo a un bebé borrego o un pollo, y que eso también es malo, también he soñado que abrazo a un puerco, por eso dejan su frialdad.

El hecho mismo de soñar puede aludir a una situación directa de causa/efecto entre el contenido del sueño y sus efectos en la salud. Al respecto, el sueño narrado por una mujer que padecía dolor e hinchazón de pies, resulta elocuente:

Que es puro potzlom, también ilbajinel, pero antes de que me enfermara soñé que unos perros negros, eran tres los negros y un rojo, me mordieron; el perro rojo me mordió la mano, y los perros negros me mordieron la cara, el cuello, y mis pies, así empezó mi enfermedad, me puse grave... yo misma puse mi vela, le hablé a nuestro Señor para que no sucediera nada, pero ya no le valió, me empezó el fuerte dolor del cuello, de mi pie, de mi cabeza, todo ahí donde me mordieron los perros.

Ya he referido que las tensiones vividas por los chamulas resultan ser detonantes de algunos padecimientos. En relación con ello, cabe preguntarse hasta qué grado los sueños narrados por los informantes, por sus características, también operan en el mismo sentido, es decir, si constituyen una fuente más de tensión que incide directamente en la salud. Esta idea es fuertemente sugerida por el siguiente testimonial de una mujer con diabetes. Es de obviar, sin embargo, que los sueños mismos, aun como eventos situados en los dominios de lo espiritual, no dejan de ser un reflejo de las circunstancias que privan en las esferas de lo terreno. Los sueños se expresan, por tanto, como un campo privilegiado para vivenciar las emociones.

...ahorita ya no, antes sí soñaba mucho, pero como que se calmó, ya no sueño tanto, y sí me enfermaba cuando soñaba algo feo, veía cómo me mataban, eso soñé bastante, y aparte me mordían los perros, me hacían muchas cosas horribles, me aplastan y me violaban, me hacía despertar por ese miedo que pasó en mi sueño, a veces me tenían apretado el cuello y así me 
despierto ya con el corazón palpitando, hasta mi boca se me secaba mucho por el miedo, así por medio del sueño me enfermo.

Como grandes referentes causales, estas categorías también permiten trazar un contínuum entre diferentes signos o síntomas, amén de que desde una óptica biomédica tengan o no relación. Se trata, entonces, no solo de la memoria del cuerpo per se, sino además de su historia dentro de su mundo social de sentido.

Es esta la idea que sugiere el testimonial de una mujer quien especulaba acerca de la posibilidad de que su tos extrema, en espera de diagnóstico biomédico, era residuo de un enorme tumor en su cuello que años atrás le había sido extirpado. El vínculo que ella establece entre uno y otro signo nutría también su sospecha de ilbajinel.

Que me creció el tumor creo que ya tiene como veintisiete años, y un hijo tenía, ya va entrar de veintisiete años mi hijo y era cuando me empezó a crecer... Si era [cuando nació mi hijo], por eso no me olvido, ya venía en camino mi hijo, a lo mejor me querían matar, y yo creo que es la raíz que quedó en mi cuello, por eso me está haciendo mal, como digo fue largo tiempo que lo tuve, sólo lo vi crecer en mi cuello, después, hace como tres años todavía fue que me lo extirparon...

Sí, y yo creo que es alguna cosa que todavía quedó de ese tumor... Así como ya dije, hasta que me pusieron mi vela se me calmó el malestar, pero siguió la bola, me dio puro escozor, no fue dolor lo que me dio, era escozor pero no se aguantaba, lo rasqué bastante y como que eso no le gustó y empezó a crecer... nada le valió, tal vez porque era malo la enfermedad, en vez de que dejara de crecer, más creció; todo lo que le eché fue en vano, y sí sufrí con eso.

Dijeron que era tumor y que era maligno, como dicen mis hijos que era como rojizo: «tiene color», que dijo el doctor.

...Ah, sí, que era matador, porque puro hipo me daba ya, no se me calmaba, hasta ya sentía que me dolía el pecho por tanto, cuando me empezaba no solo tosía, venía el hipo y ya sentía que me moría, me hizo muy feo.

Sí, hasta hoy lo sueño, porque todavía no me han curado, y cuando le vemos la cara del demonio eso quiere decir maldad de algunas personas, quiere que se ponga una protección porque anda 
vagando la maldad, porque hay personas que no ponen sus protecciones y sus espíritus están atrapados, si no se pone esa protección es cuando uno se enferma mucho, tal es por eso que ya me enfermo mucho y más por mi edad.

Respecto a la última categoría señalada por la mujer ilol — ti'olal o sbiktal kontontik, corajes-, su interés reside en el hecho de que pone de relieve la influencia patogénica de una emoción, pero también porque alude a la contraparte de las ideas causativas; es decir, la noción de castigo propiciado por el desapego a determinados valores, lo que nos remite al tema de la retribución divina.

A ello cabe agregar la idea de que el ch'ulel, espíritu, de acuerdo con las explicaciones de la propia $i l o l$, puede ser perturbado a través de un padecimiento, no solo por la acción maléfica de la envidia o animosidad de alguien, es igualmente posible que la persona esté siendo presionada para aceptar un dado mandato desde las esferas de lo sagrado - por ejemplo, ser curandero-. Esta clase de ideas suelen ser propuestas por iloles.

El siguiente segmento narrado por un joven que por principio de cuentas atribuía el origen de su creciente dificultad para caminar, así como un temblor constante de sus manos, al hecho de haber incurrido en un excesivo consumo de alcohol, ilustra cómo esta clase de ideas participan en las experiencias del padecimiento. ${ }^{20}$

\footnotetext{
Los curanderos me dicen que ... es que nosotros cuando agarramos el camino de ser curanderos nos dan castigos, y así soy yo, me dieron el... no sé, que dicen los curanderos que yo voy a ser también curandero, pero no sé... Sí les creo pero no he soñado nada... [los curanderos] hasta me han dado velas, hasta me han llevado [a la iglesia]... Cosas malas sí [he soñado]. Más o menos, soñé una vez... en mi sueño me agarró unas amigas y se subieron en la espalda, en la mañana ya estaban hinchadas mis piernas... y así fue que por eso me agarró y se vio luego, y ya dejé de tomar y me llevaron allá en San Cristóbal, cuando me trajeron aquí ya no caminaba. ${ }^{21}$
}

Todo ello remite a asumir, por tanto, que las nociones del bien y del mal asociadas a la experiencia del padecer, aunque formalmente resultan distinguibles, la intersubjetividad de las arenas sociales en que los narradores se sitúan las relativiza y torna sus fronteras difusas, y por ende las de las nociones castigo o mandato divino, y brujería. 


\section{LA AMBIGÜEDAD DE LA PERSONA MORAL; SUS REPRESENTACIONES}

Hasta aquí hemos podido observar que la articulación de ideas relativas al castigo divino, la brujería, constituyen un marco interpretativo del padecimiento y el infortunio, al que la epistemología biomédica no logra tocar de fondo. Dentro del mismo, la ambigüedad moral y por ende la del carácter moral implícito en las concepciones locales referentes a la naturaleza espiritual de la persona, cuentan con representaciones que también fungen como indicativos de las causas del padecimiento.

Se dice que además del cuerpo la persona está constituida por dos entidades espirituales diferentes. Por un lado, se tiene el xch'ulel o alma que da vida al cuerpo. Por otro el xchon o animal compañero que confiere el destino y determina la actitud moral de la persona (López 2008). La distinción entre una y otra entidad, con sus denominaciones locales, ha sido descrita por diversos autores respecto a distintos grupos mayas de Los Altos de Chiapas (Guiteras 1961, Holland 1962, Villa Rojas 1963, Vogt 1969, Hermitte 1970, Favre 1971, Pitarch 1996, Page 2005).

Sin embargo, a lo largo de los años realizando investigación en Los Altos de Chiapas, he podido una y otra vez percatarme de la dificultad que la gente tiene al explicar, si es que asume que existe, la distinción, a nivel descriptivo, lingüístico o conceptual, entre una y otra entidad. Por mi parte, como Pitt-Rivers (1970), me he inclinado a asumir que tales diferencias se refieren principalmente al poder espiritual atribuido a cada persona, y con frecuencia a sus cualidades morales que la impelen a actuar positiva o negativamente, en relación con dicho poder. Podría decir, por tanto, que se trata de distintas representaciones de la persona, en términos de su posicionamiento social frente a quienes interactúan con ella, ${ }^{22}$ y de su proclividad, percibida también por quienes le rodean hacia el «bien»o hacia el «mal». Se trata así de representaciones de una persona moralmente escindida, dentro de un universo social igualmente escindido, que se debate entre motivaciones íntimas y dilemas dentro de su mundo de valores y aspiraciones. 
De tal suerte, la ambigüedad de todas estas concepciones constituye un amplio campo de posibilidades a la hora de especular acerca de las causas que determinan el origen y el curso de un padecimiento. Así, aunque formalmente lo parezcan, como ya se ha sugerido, en el territorio de la experiencia difícilmente son excluyentes; por el contrario, coexisten de incontables formas.

Para ejemplificar estas ideas, a continuación expongo un breve fragmento testimonial de una mujer que padecía de diabetes.

Es que estaba todo revuelto, me provocaron malos sueños; potzlom, ilbajinel, eso fue lo que me dijeron, que todo estaba invocado, pero me mejoré por la curación y de las plantas que utilizaron, a veces pienso que a lo mejor ahí me empezó el azúcar, ahora ya no he tenido esos sueños malos, tal vez porque ayuné con todo el corazón como me dijeron; ya no me ha dado seguido, ya dilató bastante.

....el ilol que de por sí me está atendiendo me dijo que tenía el don de curar, por eso te molestan mucho, y te da el ilbajinel... que por eso me molestan mucho, «pero lo puedes hacer tú sola», me dijo, y sí estoy poniendo mi vela yo sola, y como eso también le está valiendo, para que ponga mi vela, tengo que ayunar.

Yo sola [pongo mi vela], no es necesario que aprenda a ser ilol también, sólo así pongo mi vela, es que así me dijo, y sí, mi cuerpo le vale y siento el alivio, así está.

De manera similar, un joven que padecía la dificultad de caminar y la propensión a caerse al sentir sus piernas paralizadas, lo que era propiciado por situaciones que lo hacían sentirse avergonzado, ${ }^{23}$ narró el encuentro que tuvo con uno de los especialistas tradicionales con los que desde su niñez comenzó a tener contacto.

Su mal había comenzado precisamente durante su temprana infancia, cuando un hermanastro suyo lo depositó sobre un pastizal.

...después llegamos con la señora y fue que nos dijo: «No, le empezó su enfermedad en donde lo acostaron de pequeño, era el camino de los padres, ${ }^{24}$ pero ya tiene tiempo, y esto ya no se puede curar porque la enfermedad ya se asentó, y ya no se puede hacer nada, o tal vez sí pero ya no es mucho lo que se puede hacer, quiere que se cure con tratamiento $\mathrm{ch}^{\text {' }}$ atael, ${ }^{25}$ quiere inyecciones, 
porque ya tiene mucha enfermedad, ya no es sólo uno su enfermedad. «Por favor, atiéndenos, entonces», le dijimos. «Yo lo que quiero es que se me cure mi pie, quiero caminar bien», le dije. «Podrías agravarte si te doy las plantas, lo que quiere es que te cure primero con velas», me dijo. «Está bien», le dijimos, vas a conseguir tres cuartos de trago [pox], o si no un litro, también quiere un pollo, huevos, pescado. Y lo que tenía, que era ilbajinel, envidias; chonel, vendido; k’op, corajes de él o de sus padres, pero todavía que lo vea primero. Pero cuando queríamos llegar a verla, ella se encontraba borracha; así siempre la encontrábamos, pero un día la encontramos: «Por favor, atiéndanos», le dijimos. «Bueno», dijo ella. «Parece que tiene un don, así como lo ven que se espanta mucho, es porque también tiene el don de curar, y lo quiere es que se le ponga de su $b a^{\prime} l e m^{26}{ }^{2} . . »$, dijo. «Háganos entonces el favor», le dijimos. «Bueno», dijo ella, y nos pidió una cruz chica y una red de velas, parece que estuvo tres días esas velas en la casa, ya no muy me acuerdo, después nos pidió una canasta y un guacal.

... y llegó el día en que me puso las velas, entonces sí me puso mi ba lem, pero fue en la iglesia, como siempre se tiene que tener el pox, entonces mis papás y la señora se pusieron a tomar, todos los gastos que se hizo ya fue por cuenta mía, mi papá ya se le había subido mucho su deuda.

Ah, sí, bueno, me pusieron mi mesa, mi ba’lem, y otras cosas más, solo que ya no me acuerdo, en fila puso mis velas, por los diferentes enfermedades que tengo, y conforme puso mis velas fue matando uno por uno los pollos...

Otro ejemplo del mismo tipo es el expuesto por una joven mujer que tenía un puesto de artesanías frente al atrio de la iglesia de Chamula, cuya hija había sufrido, siendo pequeña, graves quemaduras a raíz de habérsele vaciado encima una cazuela con aceite hirviendo. Al especular acerca de las razones que habían marcado y que aún marcaban la suerte de la niña, la madre se remonta a eventos, tanto previos como posteriores al momento en que la niña sufrió el percance.

Desde niña nació muy débil, no sé si porque me atendió dos parteras, es que no nacía mi bebé y fue que llegó la otra para atenderme y además me dijeron que tal vez estaba despreciada mi niña porque también de eso se enferman, se me puso muy flaquita, otro poco se moría, ${ }^{27}$ me la curaron de eso y sí se me curó, pero ya después que tenía ya los tres años se me quemó de aceite hirviendo, fue muy grave, se quemó el brazo, la cabeza, la cara, el estómago, lo que es la piel del estómago salió como la playera, que ahí se le vio su costilla, yo pensé que no lo iba a pasar. Mi mamá fue quien me la quemó [abuela materna de la niña], estábamos en el mercado vendiendo y mi mamá me mandó a un mandado y yo obedecí, ya de regreso ya encontré mucha gente que ya 
los tenían rodeado viendo cómo se había quemado mi niña, y sí fue muy grave, tal vez porque no era su día de morir aguantó los dolores, en su brazo se ve cómo está el hueco, y en su estómago ya no se le llenó, así quedó por las quemaduras. Cuando era más pequeña no se le entendía que era lo que decía, con mucho trabajo se le fue entendiendo, no sé si le afectó las quemaduras, porque sí le quemó mucho la cabeza, ahorita ya se le entiende un poco, no mucho, al igual con trabajo aprendió a caminar, como ya a los cuatro, cinco años aprendió, hasta ahora tambalea al caminar. Después le mandé a poner su vela para que se me ponga fuerte.

No lo sé [por qué se enfermaba mucho antes], con puros curanderos se me curó, así era a cada rato, hasta que lo curaron de su komel porque su espíritu se había quedado aquí, ${ }^{28}$ dicen que a lo mejor este lugar está muy vivo, ${ }^{29}$ tal vez es por eso que no se me curaba bien, con trabajo se me puso fuerte.

A lo mejor sí [tengo enemigo], porque no todos nos caemos bien, y sí hay algunos problemillas por ahí, pero sí le valió un poco las curaciones que se le ha hecho, y es por eso que ya ves como está.

Antes vendíamos palomitas y chicharrones, y fue ahí donde la niña alcanzó a tirar el aceite, pero no estoy segura si fue mi niña o fue mi mamá, porque no la vi. Y también aquí es muy viva la tierra porque desde recién nacida se enfermaba mucho y después se quemó en el mismo lugar.

Antes sí le dolía mucho, como mandé que le pusieran su vela de su komel, como le valió ahora rara la vez que le empieza, pero es en el brazo que le empieza a doler... Son unos dolores fuertes que le da, son como picaduras... y luego no la deja dormir por lo mismos dolores que le da.

Cuando la curan o mando a poner su vela tarda en que le vuelve a empezar, como cada mes... Tal vez por las malas envidias que hay [le vuelve a empezar].

Siempre hay, hay unos dos que tres [que no me pueden ver]... Bueno, sí hay unos por ahí, las personas envidiosas.

\section{LA INCERTIDUMBRE EN TORNO A LA VIDA SOCIAL Y LOS CONSTRUCTOS NARRATIVOS EN TORNO A LA ENVIDA Y AL CONFLICTO}

De acuerdo con algunos segmentos testimoniales hasta aquí expuestos, se puede decir que las ideas causativas se refieren a un vasto campo de factores que se sugieren más allá de los eventos concretos pero que son omnipresentes a la hora de dar cuenta del 
acontecer humano. Una energía telúrica perennemente activa en torno a la suerte de quien permanece sujeto a su influencia, las acciones de adultos cuyas consecuencias recaen en su progenie, e inclusive la envidia que parece flotar permanentemente en el ambiente y concretizarse en toda suerte de adversidades, se trata sin duda de ideas que hablan de la ansiedad que genera la incertidumbre en torno a las fuerzas que rigen el acontecer humano. Sin embargo, al menos algunas de estas ideas cuentan con fundamentos más concretos dentro de las esferas de la vida terrena.

En gran medida, esta clase de conjeturas está asociada a algunas ideas fundamentales acerca de la vida social y quizá en menor grado moldeadas por las condiciones de vida que no solo los chamulas, sino que muchos indígenas, enfrentan. Por un lado, se puede hablar de una desconfianza básica y necesaria hacia el prójimo, cualquiera que sea la actitud que este mantenga para con uno. En relación directa con ello, suele asumirse que el bienestar propio, cualquiera que sea su manifestación, resulta un motivo suficiente para mover a la envidia a quien sea.

Un ejemplo de ello es expuesto por la nuera de la mujer que padecía embolia:

Pues, quién sabe, como tenemos un pequeño negocio lo que es de las velas, hay varias que también tienen, a lo mejor les cae mal y no les gusta.

Sí, por la competencia, y como ella es dueña de casa la gente no le gusta, y supuestamente ella es la que iba a morir, no mi suegro, porque él estaba bien, según como nos han dicho y gracias a Dios no fue así, fue de otra forma. ${ }^{30}$

En un contexto donde las condiciones de vida que acompañan a ciertas personas resultan tan precarias, no deja de llamar la atención lo paradójico de algunas argumentaciones en torno a la envidia.

Una de ellas es claramente ilustrada con el siguiente segmento, referido por una mujer que padecía dolor de espalda, de manos, que presentaba problemas de menstruación, y 
quien atribuía parcialmente a la envidia que su trabajo como lavandera le granjeaba, no solo su dolor de espalda, sino también la imposibilidad de tratarse:

\begin{abstract}
Ah... sí, de que hay muchas personas que no me pueden ver sí hay, como sólo de sus trabajos y a sus casas, no les gusta que lavo, y que me conozcan [muchas personas], hasta los he visto en mi sueño que sí me quieren quitar mi trabajo... No [se dedican al mismo trabajo], no solo ellos, también hay personas que no me pueden ver de por sí, no les gusta que así gano mi comida.
\end{abstract}

No obstante, y quizá en mayor medida, en estas percepciones también puede mediar toda suerte de conflictos interpersonales que confieren al tema de la envidia elaboraciones más enfocadas respecto al carácter contradictorio, inconsistente, y por ende paradójico, de la vida social. Esto es al menos lo que sugiere otro segmento narrativo de la mujer cuya hija había sufrido graves quemaduras:

Sí, le mando a poner velas todavía cuando veo que se pone mal, es que hay muchas envidias por lo que ya mi pareja ya no es su verdadero papá, y además le han dicho a ella junto con mi otra niña su hermanita que se salgan de mi casa que porque ya no es sus verdaderos papás con quien están. «Vete a acompañar a tu abuela ya no acompañes a tu mamá», le decían [el verdadero papá de la niña ya está muerto y es por eso que la señora rehizo su vida. Con su esposo actual ya tienen un niño de tres años]. Mi otra niña también está un poco mal, le creció muchos granos y le escuece mucho.

Sí, me han dicho [los iloles], nos han curado de eso y le ha valido, como se tiene que sacar el nombre de las personas de quienes sospechamos, entonces es necesario nombrarlos, la curación se hace de k'opetik [problemas y envidia], y sí le ha valido.

Sí, por lo de mi puesto que tengo piensan que estoy ganando mucho. Sí, pienso que también por eso mi otra hija tiene granos, porque ha habido mucha envidia con nosotras, por lo que a las niñas las han aconsejado de que dejen la casa.

Cualquier persona, como me volví a juntar y él era soltero, la gente no le gustó, son personas envidiosas, como ven que algunas se van como segunda mujer, quitan marido, en mi caso no fue así y es por eso la envidia... De mi familia nada más [vienen las envidias], es que tengo una media hermana por parte de mi mamá, y es ella que no me lleva, es que ella llegó a ser segunda mujer... Así es [ella quería ser primera mujer], pero como no fue así le dio mucho coraje, quería 
que fuera segunda mujer o tercera mujer quizá... Yo pienso que sí [su envidia es causa de lo que les pasa a mis hijas], porque no les gusta que estoy con mis hijas, nos quieren ver mal,

...A mi mamá le hablo muy poco, mi papá ya está muerto, y ella se va más con mi media hermana, a mi no me habla bien, hasta eso ni refresco ha aceptado desde que me junté con mi esposo... además de por sí ha querido más a mi media hermana, no sé si porque quiso más a su primer marido, mi papá fue el segundo... Como [mi hermana] aparenta ser muy buena, y por los chismes que le mete a ella, es que inventa muchas cosas de mí y mamá le hace caso, como la quiere mucho a ella...

\section{LA OTRA CARA DE LA INCERTIDUMBRE}

Existe sin embargo un rostro opuesto de esta desconfianza, el cual apunta hacia la dificultad que cada individuo enfrenta a la hora de juzgar la calidad moral de sus propias posturas y acciones, y a través de ello escudriñar las causas detrás de su padecimiento/infortunio. Para la persona, se trata de la disyuntiva de evaluar si alguna de sus actitudes o acciones le ha acarreado la retribución divina o bien el enojo de quien sospecha le ha enviado algún mal.

Los segmentos narrativos que a continuación se presentan fueron expuestos por un hombre que no podía encontrar alivio para el mal de insomnio ni el de frialdad estomacal que le aquejaba, mismo que se originó al momento en que accidentalmente le cayó diésel en su abdomen. Como se puede observar, ambos aluden a un mismo evento, con lo que ambas lecturas del mismo, se podría decir, resultan las dos caras de una moneda.

Yo pienso que sí [que alguien pude haber perjudicado mi espíritu], cuando pasé de comité, primero trabajé cuando fue elección de presidente en electoral federal, ahí estuve sano, cuando terminó ese trabajo de la elección 2006, me dieron el cargo de comité de educación de la escuela, parece que ahí nomás encontré mi enfermedad, lo que pasa es que hubo cuatro problemas que resolví, hubo dos niños que no querían estudiar, mandé traer a los papás de los niños para que exijan a sus niños a que lleguen a la escuela y si no quieren llegar tiene remedio, sería dar la multa; les dije: «Estos dos niños, niña y niño de por sí que cada año faltan mucho, no les gusta», los ex comités no resolvieron, así quedó pendiente. El director de la escuela me pidió favor de que viera el caso [de] por qué estos dos niños ya no obedecen: «¿no sé qué remedio que puedes 
hacer por estos dos niños?», me dijo. «Vamos a mandar a traer las mamás de los niños para recomendarles que lleguen sus hijos y si no llegan van a pagar multa», le dije. Así les dije a las mamás de los dos niños pero no hicieron caso, otra vez el director nos volvió a pedir favor y ya los comités decidimos pedirles la multa, fue muy caro, fue de cinco mil pesos y ellos lo pagaron, pues ahí es donde pienso que les cayó mal a las personas.

No, antes de que pedí la multa que fue en la fecha 29 de mayo, y mi enfermedad empezó en 20 de junio, no sé si sepa usted que cuando hay problema a los cuatro días llega un zumbido de oído, porque así sentí unas tres cuatro veces a media noche cuando todavía estaba bien, antes de que empezara mi enfermedad, y es malo escuchar eso... Pues así me habían dicho mis difuntos padres, que es malo, que hay alguien que nos envidia y que rezan en la noche, así decían y así pensé pero yo no le hice caso, «total que estoy bien», dije, cuando pedí la multa hubo una razón, ahora que estoy mal, pues estoy pensando que sí tal vez hay personas que tienen coraje y que saben de la brujería, así sólo estoy pensando.

II

Ya hubo personas que trataron de convencerme [para cambiar de religión], que a lo mejor es por alguna culpa o pecados míos que estoy mal, pero ahora no muy me da tiempo... Todavía lo estoy pensando... ¡Ah, sí!, estoy pensando que sí a lo mejor es mi pecado, por eso no estoy bien, como pedí una multa estoy arrepentido porque perjudiqué a mis compañeros, porque el dinero no se consigue tan fácil.

Sí [fue dura para ellos la multa], por eso estoy arrepentido, porque el dinero no se consigue fácil, así pienso que a lo mejor sí es mí pecado, por eso estoy enfermo.

...Fue decisión de todos los padres de familia, así como en los parajes tomaron esa decisión de quienes no quieran estudiar y salgan de la escuela sin terminarla tienen que ser multados por esa cantidad de cinco mil pesos, son acuerdos que tomaron ellos mismos, pero cuando multamos a los papás de los niños ya sólo fue entre nosotros los comités, como ya se sabía cuánto les íbamos a pedir...

Como ya he mencionado, dentro de este mismo marco lógico tienen cabida las especulaciones acerca de las razones por las cuales no se puede recuperar la salud. Ello queda plenamente ilustrado por un breve fragmento testimonial referido por una mujer con diabetes que había decidido, desde tiempo atrás, cambiar de religión. 
No fue por eso [por buscar sanarme], ya tiene tiempo que entré en esa religión, sólo que no lo llevaba a cabo la palabra de Dios, no iba seguido al templo, como tengo mi pequeño negocio de frutas allá en San Cristóbal es por eso que no voy seguido al templo, hasta ahora no voy seguido, sólo el nombre le tengo, tal vez es por eso que no me sano, porque no voy seguido.

\section{LOS PROCESOS INTERPRETATIVOS, LOS PROCEDIMIENTOS RITUALES, EL UNIVERSO ONÍRICO Y SU ARTICULACIÓN CON LA EXPERIENCIA}

De manera parcial, la indagación acerca de estas posibilidades causativas es emprendida por los terapeutas tradicionales, ya sea locales o bien de otras zonas indígenas. Los procedimientos diagnósticos más comunes entre los terapeutas indígenas son el pulseo y la observación de velas mientras se reza. Es posible, también, que se recurra a otro tipo de especialistas, entre los más comúnmente mencionados se encuentran los espiritistas, a quienes sin embargo suele vérseles como embusteros. Pueden ser mestizos o indígenas. 31

A través del diálogo que las personas enfermas y sus allegados refieren haber mantenido con estos terapeutas, y de acuerdo con los efectos posteriores respecto a su estado de salud, es que se descartan o consolidan determinadas ideas causativas.

Adicionalmente, tal y como varios segmentos testimoniales ya lo han mostrado, en esta lógica interpretativa el mundo onírico y todos los símbolos que en él fluyen constituyen un referente de primer orden para nutrir todas estas ideas. ${ }^{32}$ Desde la mirada local, se trata de un mundo que por excelencia expresa todo cuanto ocurre en las esferas de lo espiritual, que puede a su vez ser pensado como un universo metafórico de todos aquellos aspectos de la vida social sujetos a conjeturas, como por ejemplo las identidades espirituales y motivaciones ocultas de las personas. Se trata de un campo de indagación al que recurren cotidianamente los chamulas, en busca de respuestas a todo acontecimiento que acompaña a sus vidas.

El siguiente segmento, narrado por una mujer que padecía dolor y frialdad de espalda y manos, así como problemas de menstruación, quien atribuía parcialmente a sus males su oficio de lavandera, ilustra cómo opera la lógica interpretativa de los sueños. 
[El ilol me dijo] que era puro potzlom. «Es potzlom lo que tienes en el estómago, son puras frialdades», me dijo, y como no me he cuidado, me he dedicado mucho a lavar, no he podido cuidarme, pero me ha dicho, «quiere que se caliente tu estómago, para eso te tengo que meter en el temascal y puras hierbas», me dijo la ilol, pero como lavo no me ha dado tiempo... Yo pienso que sí hay personas que no nos pueden ver... porque el potzlom es frialdad y se queda en el estómago, que llega por medio de los sueños, pero así muy feos, así como nos violan... Sí [he soñado así], a veces así entre mujeres o si no con mujeres mestizas, pero eran como unas pesadillas, casi fue seguido... Me violaban, eran como hombres, y por eso dicen que eso es frialdad que se queda en el estómago, también el mismo demonio nos llega a tocar en el sueño y también deja su frialdad. Es pura frialdad y es por eso que estoy así. Así es [no podía llevar ese tratamiento porque] es de cuidarse y también si es de mi komel es ahí donde no puedo hacer nada, porque no hay dinero... Sí [es de mi komel], porque la ilol me dijo que parece que sí tengo: «yo creo que es tu komel porque siento tus manos congeladas», pero no sé si es komel lo que tengo.... Todavía no [me he curado] de mi komel, pero hubo otro ilol que me dijo que parece que es chonel: «lo siento frío tus manos», me dijo, pero yo digo que de los dos, el komel y el chonel, porque he soñado varias veces que estoy en el panteón, he visto que me están midiendo ya mi tumba, así he estado soñando con esos lugares, y yo pienso que sí habrá alguna persona que sí me está vendiendo, que a lo mejor sí han puesto sus velas para que sí me enfermé, ${ }^{33}$ porque así dicen las personas que si uno lo ve en sus sueños es que sí es cierto, que sí hay personas que sí realmente nos están vendiendo, como dice el ilol que mis manos están muy frías y pueda que sea de mi komel.

Si bien se asume por un lado que la envidia en torno al bienestar propio suele ser presentada con un rostro anónimo, hemos visto que ello no es indistintamente el caso; en lo concerniente a los dominios de lo onírico, la articulación entre eventos acaecidos en el mundo terreno, en el de los sueños, de los mensajes emitidos por terapeutas, así como de los temores y ansiedades de los propios sufrientes, es capaz de atribuir a la envida no solo identidad sino también motivaciones particulares. De ello, da cuenta una mujer que sufría de dolor e hinchazón de pies:

Sí tengo de por sí quién no me puede ver, todo por unos terrenos, son tres las personas que no me pueden ver... Es mi propia familia, uno es mi hermano mayor y dos sobrinos míos, como yo no estoy casada, no tengo hijos pero tengo mi terreno pues lo están peleando, quieren que les dé, 
como los veo muy malos pues no les pienso dejar a ninguno de ellos, y por eso sospecho de ellos.

Tienen [terrenos] porque [a] todos nos dejaron nuestra herencia, pero aun así lo quiere y mis sobrinos, lo que pasa es que aparte de mi herencia compré otro pedazo de terreno que sí está un poco grande, y como ven que yo sí tengo mi terreno grande pues les da coraje, tengo mi casa que no es block, es de madera y el techo de lámina, pero les cae muy mal que tengo mis cositas y es por eso que me lo están pidiendo,

No [lo arreglamos con las autoridades] solo así, pero los iloles que me atendieron me dijeron que sí han pagado a alguien para que me hagan daño, y sí lo creo porque soñaba que unos toros enormes me querían cornear, otros me aplastaban la espalda, yo tratando de que no me corneara, le tenía agarrado los cuernos pero después se convertían en personas que eran de Tenejapa, y luego me dijeron que yo he sido fuerte porque los he vencido, pero no estaba yo sola, estaba con una muchacha que me ayudó. Otro sueño que tuve fue que me picó puras abejas grandes aquí atrás de mi cuello y todo esto lo que soñé fue antes de que me enfermara, pero no tardó, en mi cuello me creció la bolita que me dolía mucho, mi cabeza, mi pie, y mi espalda, pues así me dijeron los iloles, que había alguien que sí me estaba haciendo algo malo.

\section{EL DIÁLOGO ENTRE LA ENFERMEDAD/INFORTUNIO Y LA INCERTIDUMBRE; UNA HISTORIA SIN FIN}

No se puede asumir que los propios chamulas logren indistintamente trascender la incertidumbre que rige su vida social mediante la indagación que emprenden en estos dominios; en ocasiones ello parece más bien ampliar sus márgenes. Sin embargo, se puede decir, al menos, que pauta en gran medida las rutas a seguir, en su búsqueda por recuperar y mantener la salud y la buena fortuna.

En relación con todo lo anterior, algo que también se expresa de manera latente, aunque hipotética, es la idea de que recuperar la salud es posible mediante la identificación de la causa y agente causal del padecimiento/infortunio. En ello, como se puede inferir, median todos los temas abordados. Sin embargo, las narrativas muestran que esto dista de ser sustentado invariablemente por la experiencia. 
Es posible que por el contrario, una vez asumido que se ha establecido la identidad del mal, el sentido de amenaza se incremente de manera dramática.

Este parece ser el caso de la mujer que situaba su diabetes en el marco de una historia familiar matizada por las pérdidas de seres queridos. ${ }^{34}$ Pese a las dificultades económicas que decía enfrentar, intentaba, en la medida de lo posible, acudir con iloles para mantenerse protegida, junto con los hijos que le sobrevivían, de las amenazas que ella sentía se cernían en torno a ellos. Sus palabras resultan más que elocuentes.

No, tampoco el ilol sabe decir quién es el que está haciendo mal, no lo adivina, sólo dice que hay mucha envidia y que muy fuerte nos está atacando, no sabe tampoco ni yo, sólo así me dice, sólo pone la protección para que no nos llegue lo que están pensando hacer con nosotros; sí, mi hijo puso su vela hoy, ya la siguiente será mi hija, y así nos vamos cambiando, no lo hacemos todos juntos porque no hay dinero, pues sólo así, pero de que sepamos quién es nuestro enemigo no, no sabemos.

No he buscado a uno que sepa bien, pero sí nos han puesto nuestra vela, no a cada rato porque hace falta dinero, sólo estoy así.

A veces [gasto] de trescientos, cuatrocientos, o menos, si me conoce la curandera no me pide nada, como ve que no tengo... depende de las curanderas, hay unas que piden muchas cosas y otras que no es a la fuerza dar el refresco, solo velas me piden, que haga el esfuerzo de buscar lo necesario, así está, porque no tengo dinero de pedirle favor a alguien que sí de verdad sabe bien.

Sí, como me han dicho que nomás que encuentre dinero que mejor ponga mi vela para protegerme con mi familia, y así hago, nomás cobro de mi Oportunidades mando a poner mi vela aunque sea una vez; y si también le viene la beca de mis hijos, igual les mando a poner sus velas, pero si no hay nada que agarrar, pues no pongo mi vela hasta que me venga mi dinero.

...hay un señor que es ahijado de la mayordoma sacramento, pienso que es la persona que nos está haciendo daño, se llama Manuel Tel tuk', unas personas me han dicho que me ponga abusada de ese señor que porque anda diciendo que se quiere quedar con mi terreno, a lo mejor fue quien mató a mis dos hijos y a mi esposo, que primero va acabar a mis hijos y después a nosotras las mujeres, así como mujeres ya no somos difíciles de vencer, pero a los hombres sí que le cuesta trabajo eliminarlos. 
Hasta en mi paraje vino la persona quien lo supo, es que vino a ser mayordomo aquí, y por eso nos lo dijo luego, que estuviéramos al tanto de lo que hace este señor.

No tenemos nada de que ver con él... Tenía su casa cerca de nosotros, lo dejó vendido y se fue a vivir en otra parte, no sé que intención tenía, porque le dejó vendido a mi difunto esposo, se lo ofreció y mi esposo, como tenia su dinero guardado le compró, pareciera bueno pero desde que se compró ese terreno ahí empezó la enfermedad, luego perdí a tres seres queridos; lo que pienso es que pueda ser ese señor, antes estábamos bien, mis hijos crecieron bien, hasta que se compró ese terreno.

Asimismo, en caso de que aun habiendo establecido la fuente del padecimiento/ infortunio, la persistencia de este puede tener otras muchas lecturas.

Entre estas se cuentan, por ejemplo, la imposibilidad de sobreponerse al poder que en las esferas de lo espiritual está incidiendo en la suerte de uno, a la probabilidad de que la persona afectada no sea sincera a la hora de expresar su fe en el acto o en el agente curativo, o la falta de autenticidad al afirmar que se está arrepentido de las actitudes o acciones que causaron el mal, o incluso que la falta en la que incurrió no resulte merecedora del perdón divino.

Se percibe, entonces, más allá del reto de vencer la incertidumbre, el de responder con actos, actitudes, pensamientos, y sobre todo con sentimientos, a las fuertes exigencias de un rígido y por lo mismo frágil orden moral que, por añadidura, enfrenta los efectos de fuertes trasformaciones sociales.

Con el fin de observar cómo estas posibilidades participan, expongo a continuación el siguiente segmento testimonial.

Me llegó de manera indirecta a través del intérprete que me había ayudado a entrevistar al joven que atribuía al consumo excesivo de alcohol su creciente dificultad de caminar y el temblor de sus manos. En una atmósfera de mayor privacidad y confianza, y porque era amigo suyo, el joven le proporcionó una narración alternativa y sustancialmente más rica, de su propia experiencia. 
Samuel confesó a Mingo, el interpreté, que en realidad él ya había comenzado a curar. Fue entonces que Mingo le preguntó cómo supo que era curandero, a lo que el aludido contestó que en un principio él no sabía porque no le puso importancia a su sueño, comenzó a contar que en su sueños le dijeron que tenía que recibir ese don para ayudar a las demás personas. Que le dieron un canasto de rosas blancas, que le dieron velas, que le dieron juncia, konkon, tilil, laurel, que era lo que podía servirle para atender a los hijos de nuestro Señor. Le dijeron que no se alzara cuando le llegaran a pedir favor, ni se negara; no supo por qué su sueño. Pasó un buen tiempo hasta que cayó enfermo gravemente, lo llevaron a la clínica; el doctor le dijo que no tenía nada.

Después lo dieron a curar por varios iloles, hasta que un señor le dijo que tenía un don, y que tenía que curarse bien para que pudiese aceptar su mesa. ${ }^{35}$ Este señor le hizo el favor de ponerle su vela, que si lo llegara a aceptar así dejaría de sufrir un poco de la enfermedad que tiene, así que lo curaron dos veces, y que le hace falta una curada para que termine de aceptar su don de ilol. Pero a Samuel le preocupa que no tiene dinero, porque no puede buscarlo, porque hace un gasto que le cuesta mucho. Hace como siete meses empezó a curar.

Entonces, que él dijo que ya empezó a curar a algunas personas, que ya sabe dos clases de curación, la primera es con velas y rezos, y la segunda es como huesero. Mingo le preguntó cómo sabe qué tipo de velas usar en cada rezo, él contestó que por medio del sueño sabe, porque nuestro Señor le dice el tipo de velas y el tamaño no tan chicas y no tan grandes, a veces le dan blancas o de color oro o dorado para que utilice, eso lo ve en su sueño, pero que si es más fuerte la enfermedad que tiene que usar tres ramas de juncia, tres ramas de laurel, tres ramas de konkon, tres ramas de tilil, que son las plantas que debe usar cuando el enfermo está grave y para que así se salve, que no cobra por su servicio, que se aviene a voluntad de la persona que quiera dar.

Mingo le preguntó también cómo supo rezar o cómo se hace; contestó que igual nuestro Señor le ha enseñado cómo debe de hacerlo, que tiene que pedirle al Dios creador y de la santa Tierra, que ya se le perdone el delito o la culpa que tiene, si es por eso que le causó la enfermedad a la persona, que así le dijeron en sus sueños, y que es la única manera de librar el alma del enfermo, porque el alma de la persona es como decir que ya está atrapada con los brujos, o los tienen ya arrojados en los camposantos o en las cuevas. Él ya ha curado a cinco personas, aparte sus familiares que ya los ha ayudado, que un día se enfermó su sobrino que también tiene problemas igual como su tío, el niño se enfermó gravemente dándole mucha temblorina, que le puso tres velas, rezando en las primeras luces del día, que ya en la tarde el niño ya estaba mejor. 
Pero Samuel está triste y preocupado porque no se puede curar él mismo, que tiene que buscar otro curandero más fuerte que él, así también le dijeron en su sueño. No se ha dado a conocer todavía, no saben que ya es un nuevo curandero del pueblo, sólo algunas que sí saben, algunas personas lo llegan a buscar en su casa para que los cure y que él no se niega; como le dijeron en sus sueños que no se negara de curar a algún hijo de nuestro Señor, que él todavía no puede salir a curar, hasta que complete las tres veces de curación, entonces sí va a poder salir a curar, que ya ha curado a su mamá, a sus hermanas, que no utiliza el trago porque así le dijeron en su sueño, y también puede recaer en el trago, así de huesero que una vez le compuso la boca de su hermana porque se le había torcido porque su marido le había golpeado.

\section{LA ENFERMEDAD/INFORTUNIO, UN LENGUAJE ARTICULADOR DE TODAS LAS DIMENSIONES DE LA VIDA SOCIAL}

Haciendo un recuento de todos los temas identificados en las narrativas, es posible observar cómo la enfermedad y el infortunio son experiencias que articulan las facetas visibles y no visibles de la vida social, Desde esta perspectiva, se puede decir que la presencia del discurso biomédico no logra constituirse plenamente como una referencia significativa capaz de alterar de fondo la visión de los chamulas acerca de los procesos que conducen a la enfermedad. Se trata de visiones omnipresentes en cada uno de los espacios en los que las personas interactúan. En la misma medida, cuando la enfermedad y el infortunio se presentan, cada arena y lo que ocurre en ella tiende a ser sometida a escrutinio.

Así, para los chamulas, los padecimientos no se circunscriben a lo médico; al ser articulados con otras adversidades, aluden a otros muchos eventos que afectan a las personas, a sus cuerpos, a sus almas, a sus seres cercanos. Transita por todas las dimensiones de la vida social, la familia, la comunidad, por espacios de mayor amplitud, a los cuales los chamulas han accedido gracias a los diversos cambios que han operado en la región, pero también por las dimensiones subjetivas e intersubjetivas de la experiencia humana. Ello supone hablar de múltiples contextos y acontecimientos que en ellos tienen lugar a la hora de trazar el origen, y aun la permanencia de la enfermedad y el infortunio. 
Un último testimonial narrado por un anciano, que atribuía la diabetes de su mujer y un mal aire que afectaba sus huesos a la siguiente historia... ilustra claramente lo que puede ocurrir cuando un conflicto transita por todas estas dimensiones, pero sobre todo pone claro que desde la perspectiva de algunos chamulas las amenazas invisibles de la vida social resultan las más complicadas de contrarrestar:

Cuando mi nieto se divorció con su esposa, entonces sólo nos quedamos los dos y la verdad nos quedamos muy tristes y no hay nadie a quien hablar, entonces fuimos a pedirle a que regrese en la casa. Fue tres veces, la mujer soportó de los golpes, pero no era pocos los golpes sino muy fuertes y ella la aguantó, pero mi nieto le dice a su esposa: «está bien que me amas pero no entiendo que no sales de la casa y me dejas en paz, no soy el único y ni siquiera eres tan bonita que no te despegues de mí», pero ya no estaba tomando cuando le estaba diciendo eso, y le dije: «no te divorcies, mejor le vamos a contar al presidente», entonces se enojó mucho y entró en la casa con un azadón para matarla y llegó aquí parado debajo de mi cama, pero antes escuché la puerta que se abrió muy fuerte en la segunda planta y ya era las ocho de la noche, pero estaba consciente porque caminaba bien y sólo un poco lo tomó para perder la vergüenza, traía un azadón en su hombro y era mi azadón que lo tenia guardado y por poco me iba matar con mi propio azadón. Yo ya estaba durmiendo pero mi esposa y mi nuera estaban parado a una lado en la cama, ya lo tenia quitado mi pantalón y solamente tenia puesto la camisa, sin pensar me levanté rápido y la agarré rápido el azadón, y creo que no tiene mucha fuerza porque lo bajé al suelo y estuvimos bien agarrados y nos caímos juntos porque me tenía bien agarrado, lo suelto el azadón pero se fue rápido a agarrarlo de nuevo, pero allí abajo allí lo tenía guardado los materiales del tejido de mi esposa. entonces lo agarré y con eso me defendí sin importar en donde llegue la paliza, porque también me hizo enojar y le dije: «peleamos y a ver a quién de los dos se va morir», estaba bien enojado, pero me la agarró de nuevo y la tiré en la esquina de la casa, pero no me ganó, yo la gané a él y se escapó cuando vio que yo estaba ganando, pero si lo sabia porque se fue a avisarle sus padres en la comunidad, después llegaron su papá y su tío, íbamos a meterlo en la cárcel porque por poco nos iba matar, pero el papá del muchacho me fue a pedirme disculpa y me dijo, «no vayas a meter en la cárcel mi hijo porque estaba ebrio». «No estaba ebrio», le dije, «si realmente estuviera ebrio no vendría aquí con el azadón a matarnos y ni tendría fuerza, voy a ir a meterlo en la cárcel, ¿él por qué nos viene a mutilar en esta forma?». «No hagas esto, discúlpalo», nos dijo su papá; entonces, entramos en razón, jejeje.

Es que ya estaba pasando, porque agarraba su pistola para dispararle a su esposa, entonces se separó la mujer, pero no dejaba de que su esposa estuviera aquí, lo mandó a encarcelarla y también me encarceló, pero cuando vamos a pedirle quejas al presidente, no nos hacía caso 
porque estaba a favor de él, y sólo nos dijo: «mejor ustedes los voy a meter en la cárcel, ustedes deben ser encarcelados», así nos dijo el presidente; es porque él [mi nieto] era chofer de un volteo, por eso lo defendía.

Aunque le expliques lo que hace pero ni te toman en cuenta, que nosotros somos el culpable y que somos iguales que su esposa, «hay que meterlo en la cárcel el viejo, la mujer y su nuera», dicen, todos decían de su cárcel y daba uno miedo de lo que dicen. Entonces me enojé y dije: «mejor voy a ir en San Cristóbal», y bajaron.

...fuimos con el judicial y él se escapó, y también las autoridades se limitaron porque ellos también tienen miedo. Después de un tiempo, cuando la mujer estaba aquí en la casa, pero la que dijo el juez con el ministerio: «dígale al juez que no puede hacer eso y tampoco tiene derecho de meterlo en la cárcel su esposa, mejor dígale al juez que no haga eso y si el juez no te quiere contesta bien, entonces me vienes a avisar de nuevo, nosotros vamos a ponernos en medio, y pero no vayas a tener miedo, no vayas a tenerle miedo, y si te contesta con regaño contéstale con regaño también», me dijo la que está en San Cristóbal; ellos son muy buenos, entonces me animaron mucho y tomé fuerza, entonces fui a verlo en su casa y le dije: «buenas, vengo a verlo y a decir a mi nieto que no se ven bien con su esposa y lo quiere encarcelarla, te pido de favor que me lo detienes», y me dijo: «ah, no sé», no me quiso contestar bien... «hablo en serio, y la verdad me dijo el juez del ministerio que ustedes se van a encargar de esa situación». «iAh!», se enojó mucho y dijo: «¡ah!, ¿fuiste a San Cristóbal?», me dijo. «¿Entonces nos dejaste abandonados y pensaste que nosotros no sabemos arreglar los problemas?», me dijo. «Entonces es lo más correcto de que ustedes sólo nos meten en la cárcel y sólo nos amenazas siempre con la cárcel, ¡pendejo!», les dije, me enojé mucho y ya le grité el juez. Él se quedó callado con los gritos que le di, con eso me tuvo miedo, y también porque me vino a ayudar una hija, que está trabajando más adelante de Tuxtla, y ella me vino apoyarme e hizo los movimientos en San Cristóbal, también ella vino hablar personalmente con el juez, ella le habló en español, como ella sabe bien hablar el español junto con su yerno que es soldado, le hablaron juntos, con esos se bajaron las autoridades, entonces es allí de donde viene la enfermedad. 


\section{CONCLUSIONES}

Mediante una lectura conjunta de los temas expresados a través de las narrativas de los enfermos y de sus allegados, ha sido posible observar que los constructos locales de lo que yo llamo el complejo enfermedad/infortunio, insistentemente trascienden el campo de lo médico para decirnos mucho acerca del carácter de la vida social en su cotidianidad.

Ello, considero, aporta luces en el cometido de entender el porqué de las reiterativas fallas de las políticas y programas de salud a lo largo de diversos periodos, por lo que se plantean reflexiones en el campo de la prevención, la detección oportuna y de las dimensiones implícitas en materia de atención y apoyo social. Es evidente que para las instituciones de salud enfocadas a cada uno de estos rubros, la lógica sociocultural que acompaña a la experiencia del padecer y el reto que ello supone permanece ausente en su mirada.

Sin embargo, más allá del campo estricto de la salud, es de destacar el hecho de que si bien la vida social de los chamulas se estructura mediante lazos familiares y comunitarios que formalmente suponen respuestas a las problemáticas de salud mediadas por solidaridad y apoyo social, el marco interpretativo en el que sitúan los testimonios parece una y otra vez dar cuenta de ideas que difícilmente pueden ser asumidas como conciliatorias. El carácter hostil y en ocasiones estigmatizador de algunas lecturas del padecimiento/infortunio se muestra poco favorable. En relación con ello, los testimonios narrados continuamente hablan de personas vulneradas por condiciones de vida tensionantes, por situaciones desventajosas, y por lazos familiares y comunitarios fracturados. Todo ello se traduce en factores que repercuten negativamente en la salud, así como en la posibilidad de contar con una atención oportuna y un apoyo solidario ante los impactos colaterales de los padecimientos.

Es evidente que ello se ve agudizado por el vértigo con el que durante las últimas décadas se han producido algunas trasformaciones económicas y por ende 
socioculturales, sin embargo, este marco interpretativo del acontecer humano se muestra capaz de exacerbar las tensiones sociales a partir de sus propios fundamentos.

Como refiere Lewis (2000) en relación con las narrativas del padecimiento, estas tienden a enfatizar el drama social como una circunstancia propicia para poner a prueba los compromisos implícitos en los vínculos sociales. Pero el carácter de las narrativas aquí analizadas parece revelar un drama continuo que reiterativamente da cuenta de lazos mediados por la desconfianza y la conflictividad implícitas en las visiones locales de la vida social que parecen verse exacerbadas por la presencia de la enfermedad/infortunio. 


\section{REFERENCIAS BIBLIOGRÁFICAS}

Angulo Barrero, J. I., 2008, «De las montañas de Chiapas al Soconusco, la selva, Cancún y ahora a Estados Unidos. Las prácticas migratorias de los campesinos indígenas de Chiapas». En Migraciones en el sur de México y Centroamérica, coordinado por Daniel Villafuerte Solís María del Carmen García Aguilar, pp. 323-342. Universidad de Ciencias y Artes de Chiapas/Editorial Miguel Ángel Porrúa, México.

Dewight, R. Middleton, 1989, «Style: The Cultural Ordering of Emotions». Ethos, v. 17 , n. 2, pp. 187-201.

Douglas, Mary, 1973, Pureza y peligro. Un análisis de los conceptos de contaminación y tabú. Siglo XXI, Madrid.

Eroza, E., 2006a, «Stories of misfortune, Affliction and Mental Illness In the Chiapas Highlands of Mexico». PhD Dissertation. Department of Human Sciences, Brunel University of West London.

2006b, «Las Crisis convulsivas entre los tzotziles y tzeltales; del don sagrado al estigma». Desacatos, n. 20, pp. 77-108, enero-abril, Centro de Investigaciones y Estudios Superiores en Antropología Social, Distrito Federal, México.

Eroza, E. y G. Álvarez, 2008, «Narrativas del padecimiento "mental”; arenas de debate en torno a las prácticas sociales y a los valores que las sustentan entre los mayas tzotziles y tzeltales del sur de México». Revista de Antropología Social, n. 17, pp. 377410. Departamento de Antropología Social, Facultad de Ciencias Políticas y Sociología, Universidad Complutense de Madrid.

Favre, H., 1971, Changement et Continuité Chez les Mayas du Mexique. Editions Anthropos, Paris, France. 
Freyermuth, Graciela., 1993, «Médicos tradicionales y médicos alópatas: un encuentro difícil en Los Altos de Chiapas». Colección nuestros pueblos. Gobierno del estado de Chiapas/Consejo Estatal de Fomento a la Investigación y Difusión de la Cultura/CIESAS-Sureste, Chiapas, México.

Freyermuth, G., Meneses, S. 2008, «De dólares e infecciones. El riesgo de ITS de la población chamula en el contexto migratorio». En De crianzas, jaibas e infecciones. Indígenas del sureste en la migración, coordinado por Graciela Freyermuth y Sergio Meneses, pp. 270-328, San Cristóbal de Las Casas, Chiapas, México.

Good, B., 1990, «Medicine, rationality and experience, an anthropological perspective», pp. 135-165. Cambridge University Press, G. B.

Groark, Kevin, 2005, «Pathogenic Emotions: Sentiments, Sociality, and Sickness Amongst the Tzotzil Maya of San Juan Chamula, Chiapas, Mexico». PhD Dissertation for University of California, Los Angeles.

Guiteras Holmes, C., 1961, The Perils of the soul. The World View of a Tzotzil Indian. The Free Press, New York, USA.

Harman, R. CH., 1969, «Medical and Social changes in a Tzeltal community». PhD in anthropology dissertation, University Microfilms, Ann Harbor Michigan.

Hermitte, H., 1970, Control social y poder sobrenatural en un pueblo Maya contemporáneo. Instituto Indigenista Interamericano, Ediciones especiales 57, México.

Holland, W., 1962, Medicina Maya en los Altos de Chiapas. Un Estudio de Cambio Cultural. Traducción de Daniel Cazés. Instituto Nacional Indigenista, México, D. F. 
Köhler, U., 1975, Cambio cultural dirigido en Los Altos de Chiapas: un estudio sobre antropología social aplicada. Instituto Nacional Indigenista/Secretaría de Educación Pública, México.

Leavitt, John, 1996, «Meaning and Feeling in the Anthropology of Emotions». American Ethnologist, v. 23, n. 3, pp. 514-539. Blackwell Publishing on behalf of the American Anthropological Association.

Lewis, G., 2000, A failure of treatment. Oxford studies in social anthropology, Medical anthropology, Oxford University Press, Papua, New Guinea.

López, H. J., 2008, «La práctica médica tradicional y sus representaciones en los problemas de salud que ocasionan la muerte materna en San Juan Chamula». Tesis de licenciatura. Facultad de Ciencias Sociales, Universidad Autónoma de Chiapas, México.

Lutz, Catherin, 1986, «Emotion, thought, and Estrangement: Emotion as a Cultural Category». Cultural Anthropology, v. 1, n. 3, pp. 287-309. Blackwell Publishing on behalf of the American Anthropological Association.

Lyon, L. Margot, 1995, «Missing emotion, The Limitations of Cultural Constructionism in the Study of Emotion». Cultural Anthropology, v. 10, n. 2, pp. 244-263. Anthropologies of the Body. Blackwell Publishing onf behalf of the American Anthropological Association.

Page, J. T., 2005, El Mandato de los Dioses: Etnomedicina entre los tzotziles de Chamula y Chenaló, Chiapas. Programa de Investigaciones Multidisciplinarias sobre Mesoamérica y el Sureste, Instituto de Investigaciones Antropológicas, Universidad Nacional Autónoma de México, México, D. F.

Pitarch, P. R., 1996, Ch'ulel: una etnografia de las almas tzeltales. Fondo de Cultura Económica, México. 
Pitt-Rivers, J., 1970, «Spiritual Power in Central America: The Naguals of Chiapas». In Witchcraft Accusations and Confessions, editado por M. Douglas. Tavistock, A.S.A, Monographs 9, London, pp. 183-206.

Rebhun, L. A., 1993, «Nerves as Emotional Play in Northeast Brazil Medical Anthropology Quarterly». New Series, v. 7, n. 2, pp. 131-151. Blackwell Publishing on Behalf of the American Anthropological Association.

Reddy, William M., 1999, «Emotional Liberty, Politics and History in the Anthropology of Emotions». Cultural Anthropology, v. 14, n. 2, pp. 256-288. Blackwell Publishing on Behalf of the American Anthropological Association.

Roseman, Marina, 1990, «Head, Heart, Odor, and Shadow; The Structure of the Self, the Emotional World, and Ritual Performace among Senoi Temiar». Ethos, v. 18, n. 3, pp. 227-250. American Anthropological Association.

Rosenwein, Barbara H., 2002, «Worrying About Emotions in History». The American Historical Review, v. 107, n. 3, pp. 821-845. American Historical Association.

Rus, Jan, 1995, «La Comunidad Revolucionaria Institucional: La subversión del gobierno indígena en los Altos de Chiapas, 1936-1968». En Chiapas, Los Rumbos de Otra Historia, editado por Juan Pedro Viqueira y Mario Humberto Ruz. Centro de Estudios Mayas, Instituto de Investigaciones Filológicas y Coordinación de Humanidades, UNAM/Centro de Investigaciones y Estudios Superiores en Antropología Social/Centro de Estudios Mexicanos y Centroamericanos de la Universidad de Guadalajara. México, pp. 251-278.

Rus, D. y J. Rus, 2008, «La Migración de Trabajadores Indígenas de Los Altos de Chiapas a Estados Unidos, 2001-2005: El Caso de San Juan Chamula». En, Migraciones en el sur de México y Centroamérica, coordinado por Daniel Villafuerte 
Solís y María del Carmen García Aguilar. Universidad de Ciencias y Artes de Chiapas/Editorial Miguel Ángel Porrúa, México, pp. 343-382.

Sheper Huges N. Lock M., 1987, «The Mindful Body: A prolegomenon to Future Work in Medical Anthropology». Medical Anthropology Quarterly, New series, n. 1, pp. 6-41. The American Anthropological Association.

Skultans, V., 1998, The testimony of our lives: narrative and memory in post-soviet Latvia. Routledge, London/New York.

Turner, V., 1968, The Drums of Affliction. A Study of Religious Processes among the Ndembu of Zambia. Oxford Clarendon Press, England.

Villa Rojas, A., 1963, «El Nagualismo como recurso de control social entre los grupos mayences de Chiapas México». Estudios de Cultura Maya, n. 3, pp. 243-260. UNAM, México.

Vogt, E. Z., 1969, Zinacantan a Maya community in the Highlands of Chiapas. The Belknap Press of Harvard University Press, Cambridge, Massachusetts.

Wikan, Unni, 1989, «Managing the heart to Brighten Face and Soul: Emotions in Balinese Morality and Health care». American Ethnologist, v. 16, n. 2, pp. 294-312. Blackwell Publishing on Behalf of the American Anthropological Association. 


\section{Notas} ${ }^{1}$ Actualmente Chamula ya figura entre los principales municipios chiapanecos receptores de remesas
monetarias provenientes de Estados Unidos de Norteamérica, EUA (Jáuregui, Ávila, Coespo 2007. Citados por Freyermuth y Meneses, 2008).

${ }^{2}$ Hay quienes de manera conjetural consideran que en realidad hay gente del municipio que está inserta en redes más amplias de narcotráfico, aunque también, por estudios recientes aún sin publicar, se ha sabido que en efecto hay quienes se han insertado en ellas.

${ }^{3}$ Acerca de estos últimos, se me ha comentado por ejemplo que durante los días previos a la llegada de las antorchas guadalupanas, es decir, de peregrinos que se dirigen al santuario de la Virgen de Guadalupe en San Cristóbal de Las Casas, algunos chamulas los trasportan desde zonas fronterizas hasta San Juan Chamula para que pasen de manera desapercibida ante las autoridades migratorias. En ocasiones, los centroamericanos en tránsito de allá se disgregan, pero en otras son los propios chamulas quienes les llevan a puntos más distantes de la frontera sur, lo que puede incluir el cruce de la frontera norte.

${ }^{4}$ Los autores mencionan que linchamientos ocurridos en Chamula, a finales de la década de 1990, por causas aparentemente triviales, y en años recientes el saqueo de comercios y la destrucción de vehículos en la zona del mercado de San Cristóbal, como respuesta de chamulas organizados frente a la intervención judicial para el decomiso de productos piratas, son muestras de su relativa autonomía respecto de la normatividad.

${ }^{5}$ Viviendo en San Cristóbal, por ejemplo, se escucha tanto en los medios como a través de comentarios entre miembros de la sociedad civil, de toda suerte de actos delictivos que ocurren en los municipios indígenas, o bien en la misma ciudad, perpetrados por indígenas. Ello no quiere decir que en este último caso invariablemente sean indígenas los involucrados.

${ }^{6}$ Esto resulta fácilmente observable en referencia a la videopiratería y a la comercialización ilícita de madera en la zona de la Hormiga, colonia de migrantes chamulas en el norte de San Cristóbal; Rus (1995) refiere algo similar en el caso del narcotráfico.

${ }^{7}$ Por ejemplo, la tala y comercialización de maderas, lo que puede ser fácilmente observado en grandes locales que ofertan madera, a la orilla del periférico, en el tramo que pasa junto a la Hormiga.

${ }^{8}$ Por ejemplo, las suegras que hacen uso de su autoridad y de circunstancias desventajosas de sus nueras, en términos de valores locales, para despojarlas de sus hijos y así beneficiarse ellas, por ejemplo, con las becas escolares otorgadas por el Programa Oportunidades. Es pertinente aclarar que no se trata ni con mucho de una problemática exclusiva de los chamulas.

${ }^{9}$ Destacan la diabetes y la hipertensión, que si bien constituyen los padecimientos crónicos que más se reportan en el municipio, tanto por la Secretaría de Salud como por el Seguro Social, mediante el trabajo de campo resultó evidente que existen muchos más casos que los registrados. De acuerdo con datos extraídos durante 2008, tanto del centro de salud de SSA como de la clínica del IMSS, asentados en la cabecera municipal, todas las personas registradas con diagnóstico de algún padecimiento crónico presentaban diabetes e hipertensión arterial. Mientras en el caso del primero se trataba de dieciocho individuos, en lo concerniente al segundo éstos eran trece. Respecto al Centro de salud, se trataba de diez personas con hipertensión arterial, siete con diabetes, una con hipertensión arterial y diabetes, y una más con el diagnóstico de obesidad. De todas éstas, sólo una era del sexo masculino y se contaba entre las diabéticas. Once residían en la cabecera municipal y seis en parajes pertenecientes al municipio. En relación con la clínica del IMSS, se trataba de cinco personas con hipertensión arterial y ocho con diabetes. Seis eran mujeres, dos con hipertensión arterial, cuatro con diabetes, y siete hombres: tres con hipertensión arterial y cuatro con diabetes. Seis eran residentes de la cabecera municipal, mientras que siete habitan en parajes.

${ }^{10}$ Es de obviar que dicho diagnóstico fue proporcionado por una instancia biomédica.

${ }^{11}$ Literalmente, «el que ve», es el término en que se denomina en tsotsil a los terapeutas tradicionales que diagnostican mediante el pulseo o a través de la observación de velas mientras rezan.

${ }^{12}$ Poligina es el término antropológico para denominar a la práctica de tener más de una esposa por parte de los hombres.

${ }^{13}$ Se dirige a la intérprete.

${ }^{14}$ «El que ve» o vidente en tsotsil, término con el que son nombrados los terapeutas locales que basan sus diagnósticos en el pulseo, en sueños, en rezos y en la observación de los patrones que adquiere la cera de las velas encendidas. 
15 Literalmente, «el que ve», término tsotsil otorgado a los terapeutas tradicionales que basan sus diagnósticos en sueños, rezos y pulseo y/o interpretación de los patrones formados por la cera de velas encendidas.

16 Identifiqué una vez a un hombre que vendía bolsas de hierbas para diversos males, entre ellos la diabetes. Era un indígena que venía de la zona de Ocosingo, quien mencionó que para los diabéticos tenía dos tipos de hierbas y que las recetaba de acuerdo con la complexión de la persona: si era obesa debía tomar una que costaba seiscientos pesos, pero que si se trataba de una persona delgada el tipo de yerba que requería costaba dos mil trescientos pesos.

${ }^{17}$ Entre quienes promueven y ofertan dentro del municipio esta clase de productos, hay quienes han alcanzado cierto nivel de éxito económico y quienes también se han convertido en una suerte de actores relevantes en el campo de la atención a la salud, gracias a la capacitación que se les da por la compañía, antes de comenzar a ofrecer los productos.

${ }^{18}$ Ella es ilol.

${ }^{19}$ Ello se relaciona también con la idea, ampliamente documentada por estudios sobre estos temas en Los Altos de Chiapas, de que el alter ego, principalmente animal, de cada persona es extraído del sitio en el que permanece protegido por las deidades para que no sufra daños ni tampoco su contraparte humana.

${ }^{20}$ Se decía entre quienes lo conocían más de cerca, que había sido asiduo al consumo de la cocaína.

${ }^{21}$ Además del mal que aflige a una persona, cuando se asume que éstos se relacionan con esta clase de mandatos, los sueños son visualizados como el espacio en el que el individuo elegido debe dar constancia de su fortaleza espiritual, superando diversas pruebas, ya sea derrotando a entidades, así como dar fe de su calidad moral. También por vía de los sueños, la persona adquiere los conocimientos particulares con los cuales habrá de ejercer el rol que le está siendo asignado.

${ }^{22}$ En los textos de algunos de los autores mencionados en el párrafo previo, se dice que el poder es socialmente atribuido a la persona en función de su prestigio social. Por mi parte, dado que hoy día la idea del prestigio en términos de la tradición se percibe en franca decadencia, prefiero ampliar este marco de referencia hacia la noción de posicionamiento social.

${ }^{23}$ Es de destacar que durante la entrevista que se le hizo al joven, ocasionalmente parecía no atender a determinadas preguntas y sí a continuar refiriendo cierto evento. Algunas veces contestaba la pregunta una vez completado cierto segmento narrativo.

${ }^{24}$ La expresión se refiere a que el joven se enfermó en su niñez como consecuencia de haber incurrido, sus padres en un acto reprobable que trajo como consecuencia el padecimiento de su hijo.

${ }^{25}$ Ahumar con plantas.

${ }^{26}$ La mesa de los santos que colaboran en las curaciones, que cada persona que ha recibido el mandato de ser ilol ha de recibir.

${ }^{27}$ Despreciada por su propia familia como la abuela, o el mismo papá, hermanos, etcétera.

${ }^{28}$ En el lugar de la entrevista se había quemado la niña; está frente al atrio de la iglesia.

${ }^{29}$ Se dice que hay partes de la tierra que habitan espíritus o ángeles de Dios, y es por eso que atrapan al espíritu de las personas quienes la cruzan.

${ }^{30}$ Lo que la informante está explicando es que el mal motivado por la envidia que la mujer inspiraba recayó en su esposo, lo cual fue corroborado por la muerte de éste.

${ }^{31}$ Un hombre chamula me comentó que se incluye en esta categoría a aquellas personas que cuentan con una caja la cual contiene a un santo parlante, que en cierto modo funge como oráculo.

32 Además del campo de lo onírico, según algunos testimonios, ciertos estados de gravedad pueden también permitir el acceso a este mundo espiritual.

${ }^{33} \mathrm{Si}$ bien encender velas y rezar mantiene fines terapéuticos, dentro del marco de creencias de los chamulas y demás tsotsiles y tseltales de la región, también puede perseguir fines diametralmente opuestos, es decir, enviar enfermedad e infortunio a la persona cuyo nombre es pronunciado en los rezos.

${ }^{34}$ La misma que había perdido trágicamente a su esposo y a sus dos hijos.

${ }^{35}$ Es decir, el altar en el que tendría a los santos a los que rezaría para interceder ante ellos por la salud de sus pacientes.

Fecha de recepción: 12 de enero de 2010.

Fecha de aceptación: 21 de abril de 2010. 